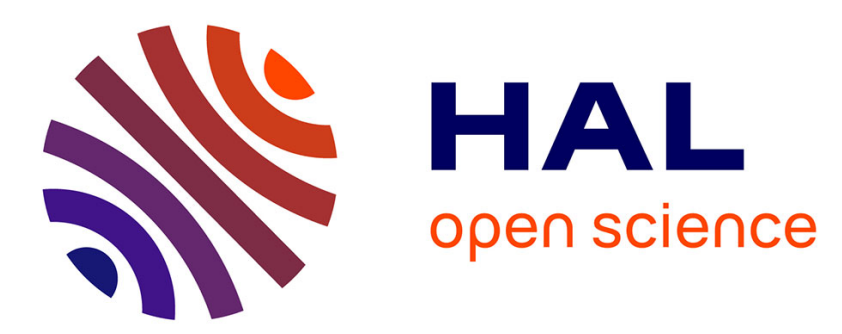

\title{
Addressing Complexity in Laboratory Experiments: The Scaling of Dilute Multiphase Flows in Magmatic Systems.
}

\author{
Alain Burgisser, Georges W. Bergantz, Robert E. Breidenthal
}

\section{To cite this version:}

Alain Burgisser, Georges W. Bergantz, Robert E. Breidenthal. Addressing Complexity in Laboratory Experiments: The Scaling of Dilute Multiphase Flows in Magmatic Systems.. Journal of Volcanology and Geothermal Research, 2005, 141, pp.N 3-4, 245-265. 10.1016/j.jvolgeores.2004.11.001 . hal00022567

\section{HAL Id: hal-00022567}

\section{https://hal-insu.archives-ouvertes.fr/hal-00022567}

Submitted on 11 Apr 2006

HAL is a multi-disciplinary open access archive for the deposit and dissemination of scientific research documents, whether they are published or not. The documents may come from teaching and research institutions in France or abroad, or from public or private research centers.
L'archive ouverte pluridisciplinaire HAL, est destinée au dépôt et à la diffusion de documents scientifiques de niveau recherche, publiés ou non, émanant des établissements d'enseignement et de recherche français ou étrangers, des laboratoires publics ou privés. 


\title{
Addressing Complexity in Laboratory Experiments: \\ The Scaling of Dilute Multiphase Flows in Magmatic Systems
}

\author{
ALAIN BURGISSER ${ }^{1}$ \\ burgisse@cnrs-orleans.fr, phone +33(0)238 2553 89, fax : +33 (0)238 636488 \\ Institut des Sciences de la Terre d'Orléans, CNRS - Université d'Orléans \\ 1A rue de la Férollerie, 45071 Orléans FRANCE
}

GEORGE W. BERGANTZ

bergantz@u.washington.edu, phone +1 206685 4972, fax +1 2065430489

Dept. of Earth and Space Sciences, University of Washington, Box 351310

Seattle, WA 98195-1310 USA

ROBERT E. BREIDENTHAL

breident@aa.washington.edu, phone +1 2066851098

Dept. of Aeronautics and Astronautics, University of Washington

Seattle, WA 98195-2400 USA

${ }^{1}$ Corresponding author

Word count: Abstract 353, Main text 7140

3 Tables, 8 Figures, 20 Equations

For submission to: JVGR 


\section{Abstract}

The kinematic and dynamic scaling of dilute multiphase mixtures in magmatic systems is the only guarantee for the geological verisimilitude of laboratory experiments. We present scaling relations that can provide a more complete framework to scale dilute magmatic systems because they explicitly take into account the complexity caused by the feedback between particles (crystal, bubble, or pyroclast) and the continuous phase (liquid or gas). We consider three canonical igneous systems: magma chambers, volcanic plumes, and pyroclastic surges, and we provide estimates of the proposed scaling relations for published experiments on those systems. Dilute magmatic mixtures can display a range of distinct dynamical regimes that we characterize with a combination of average (Eulerian) properties and instantaneous (Lagrangian) variables. The Eulerian properties of the mixtures yield the Reynolds number $(R e)$, which indicates the level of unsteadiness in the continuous phase. The Lagrangian acceleration of particles is a function of the viscous drag and gravity forces, and from these two forces are derived the Stokes number $\left(S_{T}\right)$ and the stability number $\left(\Sigma_{T}\right)$, two dimensionless numbers that describe the dynamic behavior of the particles within the mixture. The compilation of 17 experimental studies relevant for pyroclastic surges and volcanic plumes indicates that there is a need for experiments above the mixing transition $\left(\operatorname{Re}>10^{4}\right)$, and for scaling $S_{T}$ and $\Sigma_{T}$. Among the particle dynamic regimes present in surges and plumes, some deserve special attention, such as the role of mesoscale structures on transport and sedimentary processes, or the consequences of the transition to turbulence on particle gathering and dispersal. The compilation of 7 experimental studies relevant to magma bodies indicates that in the laminar regime, crystals mostly follow the motion of the melt, and thus the physical state of the system can be approximated as single phase. In the transition to turbulence, magmas can feature spatially heterogeneous distributions of laminar 
regions and important velocity gradients. This heterogeneity has a strong potential for crystals sorting. In conclusion, the $\operatorname{Re}-S_{T^{-}} \Sigma_{T}$ framework demonstrates that, despite numerous experimental studies on processes relevant to magmatic systems, some and perhaps most, geologically important parameter ranges still need to be addressed at the laboratory scale.

\section{Keywords: laboratory experiment, scaling, pyroclastic surge, volcanic plume,} magma.

\section{Introduction}

Mixtures of particles carried by liquids or gases are ubiquitous in magmatic systems. Both magma and ejecta, for example, are mixtures composed of particles (crystals, bubbles, or pyroclasts) carried by a continuous phase (melt or gas). It is axiomatic that the interplay between either silicate melt and crystals, or pyroclasts and entrained gases controls petrologic diversity and eruptive behavior, respectively, but these interactions are extremely difficult to characterize in real-time. Thus, in order to approximate the behavior of the particles entrained by magma or volcanic gases, volcanologists have traditionally simplified the dynamics by using the Eulerian approach. In this framework, one considers mean properties of the field variables (e.g., velocity, steady-state regime) and superimposes the motion that particles would have if the fluid were still. Following the same approach, laboratory experiments designed to illuminate magmatic and eruptive systems commonly considered the scaling of the mean properties of the carrier phase (i.e., Reynolds number), and the scaling between these mean properties and the solid phase properties (i.e., Rouse number). Entrainment rates of ambient air in pyroclastic surges, for example, were proposed from observations of saltwater density currents (e.g., Woods et al., 1998), and convection patterns in magmatic chambers stems from observing heated or cooled tanks of various liquids (e.g., Sparks et al., 1984; Jellinek et al., 1999). The Eulerian framework was also used to experimentally infer 
the kinematic and dynamic behavior of the particles often suspended in the natural volcanic flows. As a result, it is commonly assumed that the scaling of the continuous phase is sufficient to ensure that a laboratory experiment is a suitable analogue for a given magmatic mixture. Thus, natural volcanic mixtures are experimentally characterized by either particles settling in still fluid or well-mixed suspensions, and only the flow regions that present an endmember behavior are considered, such as the boundary layer of convecting magma bodies (Martin and Nokes, 1988) or the finest fraction of pyroclasts carried in a volcanic plume (Sparks et al., 1991).

Recent advances in the theory of multiphase physics (e.g., Raju and Meiburg, 1995; Crowe et al., 1997; Hogan and Cuzzi, 2001), however, suggest that particles do not simply follow the motions of the continuous phase, whether magmatic liquid or volcanic gas. Particle gathering and dispersal is controlled by the momentum exchange between the continuous phase and the particles. Thus, one can expect complex particle sorting to arise within flowing magmatic mixtures because non-steady processes are likely in magmatic systems. The Eulerian averaging of the flow properties, however, is not able to fully resolve the characteristic scales of particle sorting because it addresses only one aspect of their momentum exchange. This has implications for the geological verisimilitude of laboratory experiments, where kinematic and dynamic scaling are the only guarantee that entire classes of processes are not missed or misinterpreted because the laboratory scale does not adequately represent the natural systems.

Multiphase theories, on the other hand, can provide a more complete framework to scale natural volcanic systems because they explicitly take into account the complexity caused by the feedback between particles and the continuous phase. The scaling of this feedback can be achieved with a Lagrangian approach, where one introduces the unsteadiness of the flow field by using instantaneous parameters such as velocity or forces applied on a particle. Although 
multiphase physics and its application to laminar and turbulent systems are not new (Crowe et al., 1997), the application of these concepts to volcanic and magmatic systems is novel.

In this study, we present Lagrangian scaling relations that explicitly consider the unsteadiness of the fluid, and we derive the main types of particle behavior as a function of three scaling parameters: the Stokes $\left(S_{T}\right)$, stability $\left(\Sigma_{T}\right)$, and Reynolds $(R e)$ numbers. In an attempt to present an elementary tutorial in using multiphase scaling, we consider three canonical igneous systems: magma chambers, volcanic plumes, and pyroclastic surges, and we provide estimates of $S_{T}, \Sigma_{T}$, and $R e$ for published experiments on those systems. We compare the experimental ranges obtained to those of natural volcanic systems, giving an illustration of the capability of these scaling relations to achieve proper scaling of volcanic mixtures. One important conclusion is that the dynamical domains that are typical of volcanic multiphase systems remain poorly explored by the available body of experimental work.

\section{Scaling laws of dilute multiphase mixtures}

The variety of the interactions occurring in volcanic mixtures is illustrated in Figure 1. If particles interact with each other, the flowing mixture will be dominated by collisions or near-neighbor interactions, which defines dense and granular systems. Our analysis, however, is restricted to dilute systems, where particle-particle interactions are negligible, which occurs at low particle volume fraction and/or at small relative inter-particle velocity (Crowe et al., 1997). In dilute mixtures, one key control is the relative strength of the forces applied on the particles by the continuous phase versus the forces applied on the continuous phase by the particles. In our analysis, two Lagrangian parameters $\left(S_{T}\right.$ and $\left.\Sigma_{T}\right)$ assess whether the continuous phase transfers momentum to particles, which then become coupled to the fluid, or from particles, which then decouple from the fluid. When kinetic energy is continuously exchanged between fluid and particles, feedback mechanisms arise and particles tend to self- 
organize in complex patterns (e.g., Martin and Meiburg, 1994). The other key control is the amount of unsteadiness of the continuous phase, which we assess by one Eulerian parameter $(R e)$ that characterizes the dynamic state of the continuous phase in the absence of particles, an acceptable assumption for dilute flows. Whether the continuous phase is turbulent or not influences the coupling or decoupling of the particles. Turbulence tends to thoroughly mix particles that are coupled to the continuous phase ('well mixed', Fig. 1), and to segregate decoupled particles dependent on degree of decoupling (incompletely in 'mesoscale structures' or completely in 'independent trajectories'). In the laminar regime, fully-coupled particles are 'passive tracers', partly-decoupled particles drift from the continuous phase streamlines ('drifting'), and fully-decoupled particles or have 'independent trajectories' (Fig. 1).

Driven by such complex interactions, sedimentation processes vary with the multiphase behavior of the mixture, but establishing these variations is beyond the scope of this paper. In general, particles fully decoupled from the fluid settle at their Stokesian velocity $(d \widetilde{v} / d t=0$ in Equ. 1, cf. below), whereas particles fully coupled with the flow settle following an exponential decay law (Hazen, 1904; Martin and Nokes, 1989; Bursik and Woods, 1996). In laminar flows, the unsteady settling that results from the feedback between fluid and particles is poorly understood, whereas in turbulent flows, large-scale structures seem to control this regime of settling (Jopling, 1964; Niño et al., 2003; Paiement-Paradis et al., 2003).

To quantify the momentum transfer between the continuous phase and particles, we use the Lagrangian acceleration (i.e. relative to the fluid motion) of a particle in an unsteady flow; a similar approach was employed by Marsh and Maxey (1985). We express this instantaneous acceleration, which depends on the sum of the viscous and buoyancy forces acting on the particle, with a truncation of the Bassinet-Boussinesq-Oseen (BBO) equation 
valid for most magmatic mixtures (see Appendix A for the details of the simplification). The most convenient form is the dimensionless acceleration:

$$
\frac{d \widetilde{v}}{d t}=\frac{\tilde{u}-\tilde{v}}{S_{T}}+\frac{e_{g}}{F_{R}^{2}}
$$

where $\tilde{u}$ is the dimensionless carrier phase velocity, $\widetilde{v}$ the dimensionless particle velocity, and $e_{g}$ is the unit vector in gravity direction. The Stokes number $S_{T}$ and the particle Froude number $F_{R}$ are:

$$
\begin{aligned}
& S_{T}=\frac{\tau_{v}}{f} \frac{\Delta U}{\delta}\left(1+\frac{\rho_{g}}{2 \rho_{p}}\right) \\
& F_{R}^{2}=\frac{\Delta U^{2}}{g \delta}\left(\frac{2 \rho_{p}+\rho_{g}}{2 \rho_{p}-2 \rho_{g}}\right)
\end{aligned}
$$

where $\Delta U$ is the characteristic speed change of the continuous phase over the characteristic distance $\delta, g$ is the acceleration of gravity, $\rho_{p}$ is the particle density, $\rho_{g}$ is the continuous phase density, $f$ is a drag factor (Equ. A3), and $\tau_{v}$ is the particle velocity response time:

$$
\tau_{v}=\frac{\left(\rho_{p}-\rho_{g}\right) d^{2}}{18 \mu}
$$

where $\mu$ is the continuous phase dynamic viscosity.

In the particle acceleration equation (Equ. 1), the Stokes number $\left(S_{T}\right)$ quantifies the effect of the viscous drag by balancing the timescale of the fluid motion with the particle response time $\tau_{v}$, whereas the Froude number $\left(F_{R}\right)$ quantifies the inertia of the particles. To measure the balance between viscous and inertial forces, we use the stability number $\left(\Sigma_{T}\right)$, which is a ratio of Stokes and Froude numbers: 


$$
\Sigma_{T}=\frac{S_{T}}{F_{R}^{2}}=\frac{\tau_{\nu} g}{f \Delta U}=\frac{U_{T}}{\Delta U}
$$

Note that $\Sigma_{T}$ corresponds to the ratio of the terminal fall velocity $U_{T}$ of the particle and the carrier-phase characteristic speed-change $\Delta U$.

The unsteadiness of the fluid is linked to the dynamic state of the carrier phase, which is characterized by the bulk Reynolds number $(R e)$ :

$$
R e=\frac{U L}{v}
$$

where $U$ is the characteristic Eulerian speed of the system, $L$ its characteristic length (also called outer-scale), and $v$ is the kinematic viscosity of the continuous phase. At high Reynolds number, turbulence generates a whole range of eddy sizes, between the outer-scale $(L)$ and the smallest scale of eddies (Kolmogorov length scale $\lambda_{0}$ ), where the fluid viscosity dissipates the turbulent energy (Figure 2). The condition $R e \geq 10^{4}$ defines the mixing transition (Konrad, 1976; Breidenthal, 1981; Dimotakis, 2000) that separates the turbulent regime, where all length scales (eddy sizes) are present, from the transitional regime, where only some scales (eddy sizes) are present. This distinction is important when one considers a fluid loaded with particles, and it will be discussed further in the following sections. The condition $R e=1$ separates the transitional regime from the laminar regime, where the outerscale is the only length scale present (Dimotakis and Catrakis, 1999).

Our scaling analysis shows that $\operatorname{Re}$ (Equ. 6), $S_{T}$ (Equ. 2), and $\Sigma_{T}$ (Equ. 5) characterize the dynamics and kinematics of dilute multiphase mixtures. Yet, choosing appropriate scales for the fluid motions ( $U, L, \Delta U$, and $\delta$ ) to evaluate these dimensionless numbers is not obvious. $U$ and $L$ are the outer Eulerian scales for $R e$, which can be estimated from the average 
properties of the natural volcanic system (e.g., the mean current speed and thickness in postconduit flows or the mean convection speed and size in magmas, Fig. 3). $\Delta U$ and $\delta$ are the Lagrangian instantaneous scales, which vary with the dynamic object considered (e.g., eddies of various speed and size in post-conduit flows or viscous plumes of varying shape in magmas, Fig. 3). Although knowing the cause of motion (e.g., convection, buoyancy, or decompression) is essential to estimate correctly the scaling parameters, it does not affect the dynamic behavior of the mixture by itself; at equal $R e, S_{T}$, and $\Sigma_{T}$, a given mixture has a similar kinematic behavior regardless of the source of motion. In the following sections, we will consider different forms of $R e, S_{T}$, and $\Sigma_{T}$ for two magmatic mixtures: crystals/magma and pyroclasts/gas.

\section{Methods used to evaluate the scaling of experimental studies}

There is a substantial number of laboratory experiments designed to illustrate the dynamics of multiphase magmatic systems. Below, we summarize the parameter ranges of these experiments to assess their geological verisimilitude. To that end we have selected experiments (Table 1) meeting two criteria. First, the experiment has been published with, or was quoted by, work on one of the two magmatic mixtures discussed here (crystals/magma or pyroclasts/gas). Second, the experiment must explicitly address the dynamics of a multiphase system. For example, we have not included experiments attempting to address the dynamics of magma chambers from one or two-liquid systems because there are no particles in such experiments.

For each experiment, we calculated the three dynamic scaling parameters relevant to the Lagrangian-Eulerian framework of multiphase flows: $R e, S_{T}$, and $\Sigma_{T}$. Whereas estimates of $R e$ are often provided, none of the studies report the Lagrangian scaling $S_{T}$ or $\Sigma_{T}$. Thus, we 
estimated the Lagrangian scaling by using the characteristics of the particles (density and diameter) and the fluid (density and viscosity, Table 1). The characteristic length scale $\delta$ and speed $\Delta U$ are constrained by the outer-scales $L$ and $U$ (the same values as used in the bulk $R e$, Equ. 6) and the smallest unsteadiness within the flow. Because the values of the two dynamic parameters $\delta$ and $\Delta U$ considerably vary in time and space, we selected the values that maximize the range covered by the dimensionless numbers $S_{T}$ and $\Sigma_{T}$. In general, the minimum size of unsteadiness $\delta$ is the lower bound of $L$ if $R e<10^{4}$ and a tenth of that value if $R e>10^{4}$. The minimum speed of unsteadiness $\Delta U$ is the lower bound of $U$ if $R e<10^{4}$ and the quarter of that value if $R e>10^{4}$ (see section 4 below). Each experiment is thus represented by a box in the $\operatorname{Re}-S_{T^{-}} \Sigma_{T}$ space defined by the maximum and minimum values of the three dimensionless numbers. Even moderate changes (say less than an order of magnitude) on $L$ and $U$ do not affect significantly the box size at the scale we are considering: the three scalings span more than 10 orders of magnitude in all volcanic systems. It should also be appreciated that the data points collected from an experiment form either a cloud of discreet points (unique scale $L$ in laminar regime) or a volume (continuum of scales in the transitional and turbulent regimes) that does not necessarily fill the entire box. Furthermore, if some experiments systematically explore a range of $R e$, it is never the case for $S_{T}$ or $\Sigma_{T}$. Any given data set is thus likely to consist of an apparently random selection of $S_{T}$ and $\Sigma_{T}$ values, and we will discuss the implications of this lack of regularity for the geological verisimilitude of the laboratory experiments.

\section{Multiphase scaling of mixtures of pyroclasts and gas}

Post-conduit transport of pyroclasts occurs either by volcanic plumes or by pyroclastic density currents. The carrier phase is gaseous with a Reynolds number above the mixing transition $\left(R e \geq 10^{4}\right)$ and is therefore turbulent. Equation 1 is valid because the density ratio 
between particle and gas exceeds $10^{3}$ (see Appendix A). In our Lagrangian description of turbulence, we choose $\Delta U$ to be the eddy rotation speed and $\delta$ the eddy diameter to focus on the unsteadiness of the gas (Fig. 3). Therefore, $S_{T}$ is the ratio of the response time of particles $\tau_{v}$ (particle reaction to unsteady forcing by gas turbulence) to the eddy rotation time and measures the coupling between gas and particles. The term in parenthesis in Equ. 2 is equal to unity and the Stokes number becomes:

$$
S_{T}=\frac{\tau_{v}}{f} \frac{\Delta U}{\delta}
$$

Particles with $S_{T}>1$ decouple from the gas and increase the turbulence intensity of the mixture, whereas particles with $S_{T}<1$ are dynamically attached to the gas and reduce turbulence intensity. If $S_{T} \sim 1$, particles tend to gather at the eddy periphery, possibly escaping from its gyratory motion (Hogan and Cuzzi, 2001). The Stokes number controls a self-organization of the particles within an eddy, concentrating or dispersing particles as a function of their density and/or size.

The stability number is a measure of the particle residence time within an eddy and assesses the steady gravitational forcing on particles versus the viscous drag of the gas. Equation 5 reduces to:

$$
\Sigma_{T}=\frac{\tau_{\nu} g}{f \Delta U}
$$

Particles with $\Sigma_{T}>1$ are dominated by the steady acceleration of gravity and have a trajectory along the lines of this force, whereas gravity forces can be neglected for particles with $\Sigma_{T}<1$. 
Because the combination of $S_{T}$ and $\Sigma_{T}$ quantifies the effect of the fluid forces on the particles (Fig. 1), these parameters reveal whether 1) particles are decoupled from the gas and settle $\left(S_{T}>1\right.$ and $\left.\Sigma_{T}>1\right)$, or 2) particles are coupled with the gas and well mixed within the flow $\left(S_{T}<1\right.$ and $\left.\Sigma_{T}<1\right)$, or 3) a strong feedback exists between fluid and particle, creating transient particle-gathering and dispersal $\left(S_{T} \sim 1\right.$ and $\Sigma_{T} \sim 1 ; S_{T}>1$ and $\Sigma_{T}<1 ; S_{T}<1$ and $\Sigma_{T}$ $>1$ ). The two first regimes of particles behavior are similar to the ones predicted by the classical Eulerian approach. The last regime, however, leads to transient segregations of particles, which will tend to gather in zones of least velocity gradient. Resultant particle gathering causes higher particle concentrations that organize in dendritic-like patterns within the flowing mixture (Fig. 4). These ephemeral patterns are mesoscale structures, which cannot be resolved by averaging techniques (Agrawal et al., 2001; Zhang and VanderHeyden, 2002).

It is difficult to determine which unsteady scales $\Delta U$ and $\delta$ control mesoscale structures because turbulence generates a whole range of eddy sizes between $L$ and $\lambda_{0}$ (Fig. 2), and thus a wide range of $S_{T}$ and $\Sigma_{T}$ for a given particle size. Among all scales present in turbulent systems, however, there may be two length scales $\lambda_{S_{T}}$ and $\lambda_{\Sigma_{T}}$ that correspond to eddies whose $S_{T}=1$ and $\Sigma_{T}=1$, respectively. These particular eddy sizes control particle gathering and dispersal leading to the formation of mesoscale structures (Fig. 4). If the relationship between $\Delta U$ and $\delta$ is known, one can determine $\lambda_{S_{T}}$ and $\lambda_{\Sigma_{T}}$ for a given particle size. An estimate of this relationship can be done using the spectrum of turbulent kinetic energy, which describes the transfer of kinetic energy from large eddies to smaller eddy. Figure 5, for example, shows values of $\lambda_{S_{T}}$ and $\lambda_{\Sigma_{T}}$ for various particle size given by a spectrum of the form $\delta^{-8} \cdot \exp \left(\delta^{2}\right)$ (Burgisser and Bergantz, 2002). The possible emergence of mesoscale 
structures can thus be assessed as a function of particle size if the spectrum of kinetic energy is known.

It is possible, however, to narrow the range of length scales at which mesoscale structures are likely to develop in turbulent flows without knowing the specific shape of the spectrum by assuming that only the most energetic eddies control particle sorting. This assumption is less restrictive than using a particular spectrum of kinetic energy because the shape of the energetic end of the spectrum is controlled by the boundary conditions and is thus casespecific. The energy-containing range consists of the largest eddies, say from the size of the current $L$ down to an order of magnitude smaller, which corresponds to $80-90 \%$ of the total kinetic energy (Pope, 2000). Parameters $\lambda_{S_{T}}$ and $\lambda_{\Sigma_{T}}$ can be calculated by assuming that the rotation speed of these eddies $(\Delta U)$ is on the order of the root-mean-square velocity of the current, which is about $25 \%$ of its mean speed $U$. Therefore, mesoscale effects are likely to be present in a given experiment or natural case if $L<\left(\lambda_{S_{T}}, \lambda_{\Sigma_{T}}\right)<L / 10$ when $\Delta U=U / 4$.

We stress that when the flow regime is transitional, the turbulent spectrum is incomplete. In other words, $\lambda_{S_{T}}$ and $\lambda_{\Sigma_{T}}$ are not present in any given volume of the flow. Thus, $S_{T}$ and $\Sigma_{T}$ are likely to erratically jump from one value to another, thus leading to an erratic particle sorting. Note that the spatial distribution of vortices below the mixing transition is poorly understood, and thus that particle sorting cannot yet be predicted when $1<\operatorname{Re}<10^{4}$.

It has been long known that electrostatic forces can affect up to $50 \mathrm{wt} . \%$ of particles expelled by volcanic explosions, causing them to aggregate (e.g., Sparks et al., 1997). Unfortunately, the BBO equation (Equ. 1) only describes the interactions between fluid and particles, whereas electrostatic forces apply between particles. We can predict, however, that mesoscale structures are likely to favor particle aggregation because they tend to rapidly 
transport concentrations of particles across the plume/current, thereby creating favorable conditions for electrostatic interactions to occur.

\subsection{Revisiting experimental work on post-conduit pyroclastic transport}

Post-conduit pyroclastic material can be transported by either volcanic plumes or pyroclastic density currents (Fig. 3). For each of these volcanic flows, we estimated the ranges of the multiphase scaling parameters $\left(\operatorname{Re}-S_{T}-\Sigma_{T}\right)$ for the natural volcanic system and the ranges of the laboratory experiments that address the dynamics of these flows. The comparison of natural ranges and laboratory ranges of $\operatorname{Re}-S_{T}-\Sigma_{T}$ help us to address important aspects of the inherent complexity of scaling multiphase mixtures.

We estimated the natural range of the scaling parameters for volcanic plumes from representative parameters given by 1200 simulated plumes generated for 22 volcanoes in the North Pacific using the 52-years average wind speeds (Table 2; Papp, 2002). The simulations were carried out with a numerical model (PUFF; Searcy et al., 1998) that calculates the dispersion by wind of particles released at various heights above a given vent. Known eruptions were used as a reference for the simulations, from which we derived parameters of Table 2. The laboratory ranges of scaling parameters were taken from 8 experimental studies (Table 1).

We found that most experimental ranges are in the transitional regime, whereas the natural volcanic range of $R e$ lies above the mixing transition (Fig. 6A). The experiment that lies in the turbulent regime demonstrates that turbulent conditions are achievable in laboratory. The $S_{T^{-}} \Sigma_{T}$ plot shows that the experimental values fall within the range covered by the natural systems (Fig. 6B). In general, experiments overlap more than one transport regime, and were conducted at low $S_{T}$ (Fig. 6C). 
Pyroclastic density currents are composed of two end-members, dilute surges and dense pyroclastic flows, that are likely to coexist within the same density current (Fig. 3; Fisher, 1983; Valentine, 1987; Burgisser and Bergantz, 2002). We restricted the scaling of the natural volcanic systems to the surge end-member (Table 2), because the analysis proposed herein focuses on dilute systems (i.e. non-colliding particles, Fig. 1). We included the scaling parameters of a surge that occurred in 1997 at Soufriere Hills, Montserrat (Sparks et al., 2002) and the parameters of a powder-snow avalanche from observations by Bozhinskiy and Sukhanov (1998). The laboratory ranges of scaling parameters were calculated from 10 experiments related to surges and powder-snow avalanches (Table 1).

We note that several experimental studies on surges lie above the mixing transition (Fig. 7A) and thus ensure the adequate scaling of the dynamical state of the carrier phase. The $S_{T^{-}}$ $\Sigma_{T}$ plot shows a nearly complete coverage of the natural range by the experiments, although we note that only two studies focus on a specific transport regime (Fig. 7B). Interestingly, the scaling parameters of a natural snow avalanche overlap with the natural field of surges.

\subsection{Implications for volcanic plumes and pyroclastic surges}

Estimates of $S_{T}$ and $\Sigma_{T}$ in volcanic plumes and pyroclastic surges show that a systematic exploration of the mesoscale domain would doubtlessly help to clarify the relation between transport and sedimentation in these systems (Figs. 6B and 7B). Despite the known importance of the Stokes number in volcanic plumes (Kaminski and Jaupart, 1997), none of the experimental works addressing plume sedimentation report estimates of $S_{T}$ and $\Sigma_{T}$. This suggests that the role of mesoscale structures has been overlooked despite their likely occurrence in both natural systems (Figs. 6 and 7). Furthermore, when the experimental ranges we report in Figs. 6A and 7A lie below the mixing transition, the observed particle behaviors are, most likely, not representative of the turbulent natural systems. We expect 
such a discrepancy to occur because the existence of $\lambda_{S_{T}}$ and $\lambda_{\Sigma_{T}}$ are only guaranteed above the mixing transition (Fig. 2). Natural powder-snow avalanches seem to have similar kinematics as pyroclastic surges (Fig. 7), and thus experiments related to avalanches are relevant to the study of surges.

Obtaining the natural range of scales in experiments is challenging, due to the large range of $S_{T}$ and $\Sigma_{T}$ present in the natural volcanic systems and the requirement of fully-developed turbulence at the laboratory scale. Our results show that the choice of the continuous phase is crucial, and that some analogue media are more suitable than others for achieving experimental similitude. For example, water is commonly used for experimental studies of surges. Two issues, however, have to be addressed to ensure proper dynamic scaling of such experiments. First, the density contrast between particles and water has to be on the same order as the natural one $\left(10^{3}\right)$, otherwise buoyancy and virtual mass effects will significantly affect particle dynamics (cf. Appendix A). In the experiments using water as carrier liquid (Table 1), the density ratio of particle to water is systematically below 10 , two orders of magnitude lower than in the natural volcanic systems. The effect of gravity on transport of the particles is thus underestimated in those experiments. Second, all water-tank studies reported herein are in the transitional regime, suggesting that the velocities required to ensure turbulent conditions are difficult to attain in laboratory-scale water tank. Work conducted on powder snow avalanches, however, uses gas as the continuous phase, and nearly achieves fully turbulent conditions (Fig. 7). These experiments compensated the downscale in size and speed of the gaseous carrier phase by using high-density particles. Thus, the use of gas as the carrier phase eases the scaling of $S_{T}$ and $\Sigma_{T}$, but is likely to increase the working speeds up to tens of $\mathrm{m} \mathrm{s}^{-1}$. 
The Rouse number, which is the ratio of the particle terminal velocity over the Eulerian flow speed, has been extensively applied in volcanic systems (e.g., Carey, 1991). The Rouse number arises from a particular case from the diffusion equation known as the Rouse equation (Hunt, 1954; Hunt 1969; Ghosh et al., 1981) and the mixture theory used to derive the Rouse equation applies to scalar quantities advected in turbulent flows. The Rouse number has successfully been applied to tank flume experiments and correctly predicted the sediment concentration at any depth of the turbulent current (Ghosh et al., 1986). Those experiments, which had $S_{T}$ on order of $10^{-3}$, illustrate that low $S_{T}$ particles can be considered as statistically attached to the fluid. The mixture theory, however, fails to adequately represent the behavior of particles with a large $S_{T}$, typical of many natural volcanic systems. Hence, the use of the Rouse number, which derives from this theory, should be restricted to low $S_{T}$ and $\Sigma_{T}$ particles transported by flows at Reynolds number above the mixing transition.

\section{Multiphase scaling of mixtures of crystals, bubbles, and magmatic liquid}

The dynamics of magma bodies can be complex, with transient open-system processes and a variety of density changes contributing to dynamic behavior. Our intent is not to comprehensively address this complexity, but rather to consider some applications of our scaling approach to simplified magmatic applications. In magmatic mixtures, the density ratio between crystal and liquid approaches unity and the particle Reynolds number is low (i.e., $f \sim$ 1). The truncated BBO (Equ. 1) is thus valid if either the magma flows in the laminar regime $(\operatorname{Re}<1)$, or if crystals are much smaller than the unsteady structure (e.g., viscous plume). Under these circumstances, $S_{T}$ and $\Sigma_{T}$ can be reduced to:

$$
S_{T}=\frac{3}{2} \tau_{v} \frac{\Delta U}{\delta}
$$




$$
\Sigma_{T}=\frac{g \tau_{v}}{\Delta U}\left(\frac{\rho_{p}-\rho_{g}}{\rho_{p}}\right)
$$

Particles with $S_{T}>1$ are decoupled from the liquid motions. Buoyancy forces are likely to dominate their behavior, and particle motion can be described by settling in a still fluid (Stokes settling, Fig. 1). $\Sigma_{T}$ indicates whether particles settle $\left(\Sigma_{T}>0\right)$, rise $\left(\Sigma_{T}<0\right)$, or are neutrally buoyant $\left(\Sigma_{T}=0\right)$. At vanishing $S_{T}$ and $\Sigma_{T}$, particles can be considered as passive tracers, and the Reynolds number of the liquid dictates the kinematic behavior of the system. Crystal gathering and dispersal can thus be described as a chaotic advective system, which reduces the problem to a single virtual phase (Aref, 1990; Flinders and Clemens, 1996; Bergantz, 2000; Perugini and Giampiero, 2000; Perugini et al., 2002; Perugini et al., 2003). In other words, the dynamics of a slowly (laminar) convecting system is such that passive tracers drift apart (advect), and that two initially distinct populations of these tracers mix chaotically with time. Such a process is suggested by the simulations of Rudman (1992) and Simakin et al. (1997).

In magmas, the 'background' buoyancy flux is rate-limited by conductive heat loss (Smith, 1988; Marsh, 1989), with transient excursions associated with reintrusion and/or vesiculation (Bergantz and Breidenthal, 2001). Hence the continuous phase is significantly below the mixing transition, leading to two possible dynamic regimes: laminar and transitional. Motion occurs through unsteady structures such as viscous plumes, either positively buoyant (e.g., Jellinek and Kerr, 1999; Snyder, 2000; Couch et al., 2001) or negatively buoyant (e.g., Brandeis and Jaupart, 1986; Marsh, 1988; Simakin et al., 1994; Bergantz and Ni, 1999; Jellinek and Kerr, 2001). Plumes can originate from a boundary layer becoming unstable because of density changes, or because of the injection of new liquid (Fig. 3). In both cases, it is possible to define $R e$ as a function of the buoyancy flux: 


$$
\operatorname{Re}=\frac{B^{1 / 2} L^{2}}{v^{3 / 2}}
$$

where the outer-scale $L$ is the height of the system (magmatic chamber, Fig. 3), $v$ is the kinematic viscosity of the magmatic liquid, and $B$ is the buoyancy flux, upon which the velocity scale is based (see Appendix B, Equs B2 and B3).

\subsection{Revisiting experimental work on multiphase flow in magmas}

The estimation of the range of Reynolds numbers that characterizes magmatic systems is not trivial. $R e$ is sensitive to the scale studied, whether large-scale chamber dynamics, or small-scale boundary layer problems (e.g., Jaupart and Tait, 1995). Thus, the range of $R e$ varies considerably according to the magmatic process of interest. The parameter range we propose (Table 2) is representative of chamber-wide dynamics, neglecting transient local processes that may have higher $R e$, such as sidewall density current caused by crystal landslide or rapid vesiculation (Bergantz and Breidenthal, 2001). We considered that the lower bound of $R e$ is zero, as liquid velocity vanishes at the chamber wall. We used Equ. 11 to set the upper bound of $R e$, and we selected viscosities to cover a wide spectrum of magmatic compositions. We used data from Couch et al. (2001) to determine the scaling of the magmatic reservoir feeding the current eruption at Soufriere Hills, Montserrat. We calculated the scaling parameters from 7 published experiments (Table 1).

Scaling parameters of the experiments show a complete coverage of the transitional regime in the $\operatorname{Re}-\Sigma_{T}$ plot, which overlap well with the natural range we defined (Fig. 8A). The majority of the natural field of magmatic chambers is in the chaotic advective regime, in which particles are passive tracers of the flow patterns, whereas most experiments do not overlap this transport regime (Fig. 8B). Along these lines, most experiments have much larger $S_{T}$ than natural systems (Fig. 8C). 


\subsection{Implications for magmatic systems}

Crystal transport in magma chambers has previously been described by using a ratio $(S)$ based on the BBO equation (Marsh and Maxey, 1985; Weinstein et al. 1988; Rudman, 1992). Because $S$ is the ratio of the particle settling velocity to the convective velocity, it corresponds to a stability number $\Sigma_{T}$ with the characteristic velocity $\Delta U$ based on a Eulerian velocity. In other words, in the viscous regime, $S=\Sigma_{T}$ because the velocity scale is unique in viscous flows. To characterize the multiple scales of motions present in the inertial regime, however, a range of values of $\Delta U$ (velocity of the instabilities driving the flow) needs to be considered. This slightly more general definition gives the proper range of values at any Reynolds number. In any case, care should be taken in working with $S_{T}$ and $\Sigma_{T}$ in the inertial regime, because the simplification of the BBO equation (from Equ. A1 to Equ. 1) is not valid (see Equs. A5-A6). A comprehensive study of crystal behavior when $R e>1$ thus needs proper scaling of the Basset and virtual mass forces, which is beyond the scope of this paper.

Although we consider that particles with $S_{T}<1$ are dynamically attached to the liquid, they will nevertheless have a small 'drift velocity' compared to the carrier phase, unless $S_{T}=$ 0. Marsh and Maxey (1985) concluded that this drift velocity becomes important for the longterm behavior of particles trapped in a periodic flow, because it significantly affects their residence time. An even more general perspective might be that all natural flows are aperiodic, which often generate better mixing than periodic flows by greatly reducing the size of non-chaotic regions ('regular islands' in 2D laminar periodic flow, Liu et al., 1995; Solomon and Mezic, 2003). As unsteady structures are created, morph, and vanish, the drift velocities of the particles that are associated with each structure are unlikely to cumulate, but rather tend to cancel out. We thus suggest that drift velocities are negligible in the laminar case on the premise that magmatic systems are aperiodic. Note that this aperiodicity does not 
allow the practice, common in chaotic advection studies, of reducing the degrees of freedom by eliminating time using, for example, Poincaré maps (Ottino, 1990).

With these caveats, the overlap of the advective regime with the field of natural magmatic systems (Fig. 8) suggests that single-phase flows of miscible liquids approximate crystalliquid mixtures. In other words, understanding the flow field of the liquid also means understanding the motions of the crystals (Perugini and Giampiero, 2000; Perugini et al., 2003). We note, however, the paucity of magma-scaled, unseeded experiments in the laminar regime to understand crystal gathering and dispersal (e.g., Jellinek et al., 1999). On the other hand, the gap of several orders of magnitude of $S_{T}$ separating the natural field from the Stokes regime confirms the inapplicability of a simple settling law to understand crystal transport in convecting magmas, as discussed by Martin and Nokes (1988). Thus, magmatic liquids cannot be considered as motionless, which forces us to look at magmatic chambers as fundamentally dynamic systems. Hence, experiments underestimate the control of viscous drag because they have $S_{T}$ larger than the typical range of natural systems (Fig. 8B,C). As a result, the importance of small-scale unsteadiness (or accelerations) that drives crystal gathering and dispersal in magmatic chambers has been underestimated.

\subsection{Using the Lagrangian framework in magmas}

The Stokes and the stability numbers provide a means for assessing the relative motion between phases and thus whether particles present in a convective melt can separate from the surrounding liquid. We consider two practical cases: 1) particles are crystals and 2) particles are gas bubbles.

Consider the creation of an unstable boundary layer at the floor or roof of a magmatic chamber caused by thermal or compositionally induced density changes. The viscosity 
contrast between the buoyant instability (plume) and the ambient liquid controls the rate of entrainment at the plume head, and thus the speed at which plumes mix with the ambient liquid (Bergantz and Ni, 1999; Jellinek et al., 1999). We estimated $S_{T}$ and $\Sigma_{T}$ for olivine crystals in the roof or base of basaltic lava lake (Jellinek and Kerr, 2001) because, in this case, the viscosity contrast is small and the buoyancy flux is high (see Appendix B for calculations). Bergantz and Ni (1999) showed that, under the same conditions, plumes engulf ambient liquid at the head and quickly disperse, creating an efficient mixing front with no recognizable structure. Under these conditions both $S_{T}$ and $\Sigma_{T}$ are well below unity (Table 3), which indicates that crystals are unlikely to exit plumes before plume dispersal. Hence, we do not expect situations in which liquids poorly mix, but crystals disperse widely when the viscosity contrast is small.

On the other hand, a system such as Montserrat (Couch et al., 2001) has a high viscosity contrast between the heated plumes and the colder host liquid, and the shape of plumes change little during ascent, inducing slow mixing (Bergantz and Ni, 1999; Jellinek et al., 1999). We found that orthopyroxenes entrained within instabilities of heated andesite have small values of $S_{T}$ and $\Sigma_{T}$ (Table 3). Crystals thus act as passive tracers and are advected in the buoyant plumes. As the width of the plume tail diminishes, $S_{T}$ increases, but it is only when the plume width, reduced by stretching during the ascent, becomes on the order of the crystal size that $S_{T}$ approaches unity. At that point, the plume is almost completely incorporated in the convecting liquid. Hence crystals are unable to leave the instabilities until they completely mix. In summary, crystals are entrained within instabilities regardless of the viscosity contrast between the plumes and the ambient liquid, and crystals move by chaotic advection in convecting magma chambers. 
Volatile exsolution can occur at various stages of magmatism. The density contrast between bubbles in the magmatic liquid requires the assessment of their relative motion to understand the style of degassing in magmatic systems (Huppert and Woods, 2002). Under low yield stress, bubbles can be considered as buoyant, rigid spheres (i.e., the capillary number is below unity, Manga et al., 1998) with calculable $S_{T}$ and $\Sigma_{T}$. Typical $\Sigma_{T}$ range from $>1$ (basalt) to $<<1$ (rhyolite). For example, $100 \mu \mathrm{m}$ bubbles will escape from a rising basaltic liquid slower than $3 \mathrm{~cm} / \mathrm{s}$ (condition $\Sigma_{T}>1$ ), whereas the same bubbles can be considered immobile with respect to a rhyolitic liquid faster than $3 \times 10^{-7} \mathrm{~cm} / \mathrm{s}$. In other words, rising basalt stopped in its progression will lose its exsolved volatiles orders of magnitude faster than its rhyolitic counterpart will, possibly creating a foam layer atop (e.g., Thomas et al., 1993).

\section{Conclusions}

Multiphase mixtures in magmatic systems can display a range of distinct dynamical regimes that can be characterized with a combination of average (Eulerian) properties and instantaneous (Lagrangian) variables. The Lagrangian acceleration of particles is a function of the viscous drag and gravity forces, and from these two forces are derived the Stokes number $\left(S_{T}\right)$ and the stability number $\left(\Sigma_{T}\right)$, two dimensionless numbers that describe the dynamic behavior of the particles within the mixture. The Eulerian properties of the mixtures yield the Reynolds number $(R e)$, which characterizes the level of unsteadiness in the continuous phase (liquid or gas).

Pyroclasts and gas is a common volcanic mixture that forms most post-conduit flows such as volcanic plumes and pyroclastic surges. Pyroclastic surges and volcanic plumes have high Reynolds number, and therefore all scales of turbulence (i.e. eddy sizes) are present within these systems. The compilation of 17 experimental studies relevant for surges and plumes 
indicates that there is a need for experiments above the mixing transition $\left(R e>10^{4}\right)$ because lower values of $R e$ imply that parts of the flow feature an incomplete set of eddy sizes, which affects particle transport. We expect complex particle sorting to arise within surges and plumes because each eddy size segregates pyroclasts as a function of their size, which span three orders of magnitude. Eddies whose Stokes and stability numbers are close to unity are most likely to control this sorting, which forms patterns known as mesoscale structures. Particles are efficiently mixed by larger eddies (i.e. with $S_{T}$ and $\Sigma_{T}<1$ ), whereas particles decouple and sediment out from smaller eddies (i.e. with $S_{T}$ and $\Sigma_{T}>1$ ). Results from the compilation of laboratory studies show that there is a need for scaling $S_{T}$ and $\Sigma_{T}$ in experimental work, as none of the studies report the values of these two dimensionless numbers. Among the particle dynamic regimes, some deserve special attention, such as the role of mesoscale structures on transport and sedimentary processes in plumes and surges, the applicability of turbulence models below the mixing transition, and the consequences of this transition on particle gathering and dispersal. The relevance of snow avalanche studies for surges is a clear example of the links that can be drawn from the multiphase scaling relations proposed herein.

Crystals and silicate melt compose most magmatic mixtures, which are characterized by dynamic regimes ranging from laminar to transitional. The compilation of 7 experimental studies indicates that in the laminar regime, crystals mostly follow the motion of the melt, and thus the physical state of the system can be approximated as single phase. In the transitional regime, magmas can feature spatially heterogeneous distributions of laminar regions and zones with important velocity gradients because not all scales of fluid motion are present. This heterogeneity has a strong potential for crystals sorting, and not only viscous drag and gravity forces affect crystal trajectories, but also Basset and virtual mass forces. 
The $\operatorname{Re}-S_{T^{-}} \Sigma_{T}$ framework for dilute multiphase flow demonstrates that, despite numerous experimental studies on processes relevant to magmatic systems, some and perhaps most, geologically important parameter ranges still need to be addressed at the laboratory scale. The combined Eulerian-Lagrangian approach provides a quantitative template for the assessment of the adequate scaling of the interplay between particles and the continuous phase in dilute multiphase magmatic mixtures.

\section{Acknowledgments}

We would like to thank SJ Lane and an anonymous reviewer for their helpful suggestions. Funding was provided by the NSF grants EAR-0106441 to GWB and EAR-0309703 to AB. AB was also partially supported by the Volcano Hazards Program of the US Geological Survey, through the Alaska Volcano Observatory.

\section{Appendix A: Truncation of the BBO equation}

The Bassinet-Boussinesq-Oseen (BBO) equation expresses the Lagrangian acceleration of a spherical particle in an unsteady flow as the sum of the viscous, gravitational/buoyancy, virtual mass, and Basset forces acting respectively on the particle (Maxey and Riley, 1983; Crowe et al., 1997):

$$
\left(1+\frac{\rho_{g}}{2 \rho_{p}}\right) \frac{d v}{d t}=\frac{f}{\tau_{v}}(u-v)+g\left(1-\frac{\rho_{g}}{\rho_{p}}\right)+\frac{3 \rho_{g}}{2 \rho_{p}} \dot{u}+\sqrt{\frac{9 \rho_{g}}{2 \pi \rho_{p} t_{v}}}\left[\int_{0}^{t} \frac{\dot{u}-\dot{v}}{\sqrt{t-t^{\prime}}} d t^{\prime}+\frac{(u-v)_{0}}{\sqrt{t}}\right]
$$

Where $u$ is the carrier phase velocity, $v$ the particle velocity, $\rho_{g}$ is the carrier phase density, $\rho_{p}$ is the particle density, $d$ is its diameter, $\mu$ is the carrier phase dynamic viscosity, $g$ is the acceleration of gravity, $\tau_{v}$ is the particle velocity response time (Equ. 4), and $f$ is a drag factor 
valid over the entire subcritical range of particle Reynolds number $\left(R e_{p} \leq 10^{5}\right.$, Clift and Gauvin, 1970):

$$
\begin{aligned}
& f=1+0.15 \operatorname{Re}_{p}^{0.687}+\frac{0.0175}{1+42500 \operatorname{Re}_{p}^{-1.16}} \\
& \operatorname{Re}_{p}=\frac{U_{T} d}{v}
\end{aligned}
$$

where $U_{T}$ is the particle terminal fall velocity and $v$ is the kinematic viscosity of the carrier phase. The BBO equation is not solvable analytically for the particle speed, but some simplifications are possible and lead to the simple scaling laws used herein. Compared to the viscous drag $\left(F_{\text {viscous drag }}\right)$, the virtual mass $\left(F_{\text {virtual mass }}\right)$ and Basset $\left(F_{\text {Basset }}\right)$ forces are on the order of (Maxey and Riley, 1983):

$$
\begin{aligned}
& F_{\text {Basset }} \approx \sqrt{\operatorname{Re}} \frac{d}{L} F_{\text {viscous drag }} \\
& F_{\text {vitrual mass }} \approx \operatorname{Re}\left(\frac{d}{L}\right)^{2} F_{\text {viscous drag }}
\end{aligned}
$$

From Equs A1, A4, and A5, we deduce that the virtual mass and Basset forces are negligible for either $\operatorname{Re}<<1, d<<L$, or $\rho_{p}>>\rho_{g}$. If any of these conditions are satisfied, it is possible to truncate Equ. A1 and use only the viscous drag and the gravity force (Raju and Meiburg, 1995):

$$
\frac{d v}{d t}=\frac{f}{\tau_{v}}(u-v)\left(\frac{2 \rho_{p}}{2 \rho_{p}+\rho_{g}}\right)+g\left(\frac{2 \rho_{p}-2 \rho_{g}}{2 \rho_{p}+\rho_{g}}\right)
$$

Nondimensionalisation by the carrier phase time scale, which is the characteristic speed change of the carrier phase $\Delta U$ over the characteristic distance $\delta$, gives Equ. 1 . 


\section{Appendix B: Crystal settling in magmas}

This appendix presents the details of the scaling of crystals in magmatic chambers.

Crystals are entrained within unstable plumes that form at the interface between the injected or heated magma and the host magma. We recognize that the rheologic structure of the magma chamber boundary can be complex (Marsh, 1988, 1989), but will not address that complexity here. For our purposes, we address only the mobile portion of the boundary layer. The Lagrangian scaling requires the characteristic length and velocity scales of these plumes. We take the width of the Rayleigh-Taylor plumes as the length scale of the instabilities (Kerr, 1994; Jellinek et al., 1999):

$$
\delta=\frac{\sqrt{6.22 \mu_{m} \rho_{f} B}}{g\left(\rho_{f}-\rho_{m}\right)}
$$

where $\mu_{m}$ and $\rho_{m}$ are the viscosities and density of the boundary layer, $\rho_{f}$ the density of the host magma, and $B$ is the buoyancy flux (Jellinek and Kerr, 2001):

$$
B=\frac{q \alpha g}{\rho_{f} c_{p}}
$$

where $q$ is the heat flux, $\alpha$ is the coefficient of thermal expansion, and $c_{p}$ is the heat capacity of the magma. The velocity scale of the plumes is estimated from the buoyancy Reynolds number (Equ. 11):

$$
\Delta U=\frac{B^{1 / 2} H}{v^{1 / 2}}
$$




\section{References}

Agrawal, K., Loezos, P.N., Syamlal, M., Sundaresan, S., 2001. The role of meso-scale structures in rapid gas-solid flows. J. Fluid Mech. 445, 151-185.

Anilkumar, A.V., Sparks, R.S.J., and Sturtevant, B., 1993. Geological implications and applications of high-velocity two-phase flow experiments, J. Volcanol. Geotherm. Res. 56, 145-160.

Aref, H., 1990. Chaotic advection of fluid particles. Phil. Trans. Royal Soc. London A333, 273-288.

Bagnold, R.A., 1954. Experiments on a gravity-free dispersion of large solid spheres in a Newtonian Fluid under shear, Proc. Royal Soc. London A225, 49-63.

Bergantz, G.W., 2000. On the dynamics of magma mixing by reintrusion: implications for pluton assembly processes. J. Structural Geol. 22, 1297-1309.

Bergantz, G.W., Breidenthal, R.E., 2001. Non-stationary entrainment and tunneling eruptions: a dynamic template for eruption processes and magma mixing. Geophys. Res. Lett. 28, 3075-3078.

Bergantz, G.W., Ni, J., 1999. A numerical study of sedimentation by dripping instabilities in viscous fluids. Int. J. Multiphase Flow 25, 307-320.

Bonnecaze, R.T., Hallworth, M.A., Huppert, H.E., Lister, J.R., 1995. Axisymmetric particle-driven gravity currents, J. Fluid Mech. 294, 93-121.

Bozhinskiy, A.N., Sukhanov, L.A., 1998. Physical modelling of avalanches using an aerosol cloud of powder materials, Annals Glaciology 26, 242-246.

Brandeis, G., Jaupart, C., 1986. On the interaction between convection and crystallization in cooling magma chambers. Earth Planet. Sci. Lett. 77, 345-361.

Breidenthal, R., 1981. Structure in turbulent mixing layers and wakes using a chemical reaction. J. Fluid Mech. 109, 1-24.

Burgisser, A., Bergantz, G.W., 2002. Reconciling pyroclastic flow and surge: the multiphase physics of pyroclastic density currents. Earth Planet. Sci. Lett. 202, 405-418.

Bursik, M.I., Woods, A.W., 1996. The dynamics and thermodynamics of large ash flows. Bull. Volcanol. 58, 175-193.

Cardoso, S.S.S., Zarrebini, M., 2001. Convection driven by particle settling surrounding a turbulent plume, Chem. Engin. Sc. 56, 3365-3375.

Carey, S.N., 1991. Transport and deposition of tephra by pyroclastic flows and surges. In: Fisher, R.V., Smith, G.A. (Editors), Sedimentation in volcanic settings. Soc. Sedimentary Geol. Spec. Publ. 45, Tulsa, 39-57.

Carey, S.N., Sigurdsson, H., Sparks, R.S.J., 1988. Experimental studies of particle-laden plumes, J. Geophys. Res. 93, 15314-15328.

Choux, C.M., Druitt, T.H., 2002. Analogue study of particle segregation in pyroclastic density currents, with implications for the emplacements mechanisms of large ignimbrites, Sedimentology 49, 907-928.

Clift, R., Gauvin, W.H., 1970. The motion of particles in turbulent gas streams. Proc. Chemeca '70, 14-28.

Couch, S., Sparks, R.S.J., Carroll, M.R., 2001. Mineral disequilibrium in lavas explained by convective self-mixing in open magma chambers. Nature 411, 1037-1039.

Crowe, C., Sommerfeld, M., Tsuji Y., 1997. Multiphase flows with droplets and particles. CRC Press.

Dimotakis, P.E., 2000. The mixing transition in turbulent flows. J. Fluid Mech. 409, 69-98. 
Dimotakis, P.E., Catrakis, H.J., 1999. Turbulence, fractals, and mixing. In: Chate, H., Villermaux, E., Chomaz, J.-M. (Editors), Mixing, chaos and turbulence. NATO ASI Series B: Physics 373, 59144.

Ernst, G.G.J., Sparks, R.S.J., Carey, S.N., Bursik, M.I., 1996. Sedimentation from turbulent jets and plumes, J. Geophys. Res. 101, 5575-5589.

Fisher, R.V., 1983. Flow transformations in sediment gravity flows. Geology 11, 273-274.

Flinders, J., Clemens, J.D., 1996. Non-linear dynamics, chaos, complexity and enclaves in granitoid magmas. Trans. Royal Soc. Edinburgh: Earth Sci. 87, 217-223.

Ghosh, J.K., Mazumder, B.S., Saha, M.R., Sengupta, S., 1986. Deposition of sand by suspension currents: experimental and theoretical studies. J. Sediment. Petrology 56, 57-66.

Ghosh, J.K., Mazumdmer, B.S., Sengupta, S., 1981. Methods of computation of suspended load from bed materials and flow parameters, Sedimentology 28, 781-791.

Hazen, A., 1904. On sedimentation, Trans. Am. Soc. Civil Engineers 53, 45-88.

Hogan, R.C., Cuzzi, J.N., 2001. Stokes and Reynolds number dependence of preferential particle concentration in simulated three-dimensional turbulence. Physics Fluids 13, 2938-2945.

Hogg, A.J., Huppert, H.E., 2001. Two-dimensional and axisymmetric models for compositional and particle-driven gravity currents in uniform ambient flows. Spec. Publ. Int. Assoc. Sedimentology 31, 121-134.

Hoyal, D.C.J.D., Bursik, M.I., Atkinson, J.F., 1999. Settling-driven convection: A mechanism of sedimentation from stratified fluids, J. Geophys. Res. 104, 7953-7966.

Hunt, J.N., 1954. The turbulent transport of suspended sediment in open channels, Proc. Royal Soc. London A224, 322-335.

Hunt, J.N., 1969. On the turbulent transport of a heterogeneous sediment. Quarterly J. Mech. Appl. Math. 22, 235-246.

Huppert, H.E., Kerr, R.C., Lister, J.R., Turner, J.S., 1991. Convection and particle entrainment driven by differential sedimentation, J. Fluid Mech. 226, 349-369.

Huppert, H.E., Sparks, R.S.J., Turner, J.S., 1983. Laboratory investigations of viscous effects in replenished magma chambers, Earth Planet. Sci. Let. 65, 377-381.

Huppert, H.E., Woods, A., 2002. The role of volatiles in magma chamber dynamics. Nature 420, $493-$ 495.

Jaupart, C., Tait, S., 1995. Dynamics of differentiation in magma reservoirs, J. Geophys. Res. 100, 17615-17636.

Jellinek, A.M., Kerr, R.C., 1999. Mixing and compositional stratification produced by natural convection 2. Applications to the differentiation of basaltic and silicic magma chambers and komatiite lava flows. J. Geophys. Res. 104, 7203-7218.

Jellinek, A.M., Kerr, R.C., 2001. Magma dynamics, crystallization, and chemical differentiation of the 1959 Kilauea Iki lava lake, Hawaii, revisited. J. Volcanol. Geotherm. Res. 110, 235-263.

Jellinek, A.M., Kerr, R.C., Griffiths, R.W., 1999. Mixing and compositional stratification produced by natural convection 1. Experiments and their application to Earth's core and mantle. J. Geophys. Res. 104, 7183-7201.

Jobson, H.E., Sayre, W.W., 1970. Vertical transfer in open channel flow, Journal of the Hydraulic Division, Proc. Am. Soc. Civil Engineers 96, 703-724.

Jopling, A.V., 1964. Laboratory study of sorting processes related to flow separation. J. Geophys. Res. 69, 3403-3418.

Kaminski, E., Jaupart, C., 1997. Expansion and quenching of vesicular magma fragments in Plinian eruption. J. Geophys. Res. 102, 12187-12203. 
Kerr, R.C., 1994. Dissolving driven by vigorous compositional convection, J. Fluid Mech. 280, 287302.

Konrad, J.H., 1976. An experimental investigation of mixing in two-dimensional turbulence flows with application to diffusion-limited chemical reactions. Ph.D. thesis, California Institute of Technology, Project SQUID Tech. Rep. CIT-8-PU.

Koyaguchi, T., Hallworth, M.A., Huppert, H.E., Sparks, R.S.J., 1990. Sedimentation of particles from a convecting fluid, Nature 343, 447-450.

Liu, M., Muzzio, F.J., Peskin, R.L., 1995. Quantification of mixing in aperiodic chaotic flows. In: Aref, H., El Naschie, M.S. (Editors) Chaos applied to fluid mixing. Pergamon, 125-149.

Manga, M., Castro, J., Cashman, K.V., Loewenberg, M., 1998. Rheology of bubble-bearing magmas. J. Volcanol. Geotherm. Res. 87, 15-28.

Marsh, B.D, 1989. On convective style and vigor in sheet-like magma bodies. J. Petrology 30, 479530.

Marsh, B.D., 1988. Crystal capture, sorting, and retention in convecting magma. Geol. Soc. Am. Bull. 100, 1720-1737.

Marsh, B.D., Maxey, M.R., 1985. On the distribution and separation of crystals in convecting magma. J. Volcanol. Geotherm. Res. 24, 95-150.

Martin, D., 1990. Crystal settling and in situ crystallization in aqueous solutions and magma chambers, Earth Planet. Sci. Let. 96, 336-348.

Martin, D., Nokes, R., 1988. Crystal settling in vigorously convecting magma chamber. Nature 332, 534-536.

Martin, D., Nokes, R., 1989. A fluid-dynamical study of crystal settling in convecting magmas. J. Petrology 90, 1471-1500.

Martin, J.E., Meiburg, E., 1994. The accumulation and dispersion of heavy particles in forced two dimensional mixing layers. I. The fundamental and subharmonic cases. Phys. Fluids 6, 116-1132.

Maxey, M.R., Riley, J.J., 1983. Equation of motion for a small rigid sphere in a nonuniform flow. Phys. Fluids 26, 883-889.

Niño, Y., Lopez, F., Garcia, M., 2003. Threshold for particle entrainment into suspension. Sedimentology 50, 247-263.

Ottino, J.M., 1990. The kinematics of mixing: Stretching, chaos, and transport, Cambridge Texts in Applied Mathematics, Cambridge University Press, 364 p.

Paiement-Paradis, G., Buffin-Bélanger, T., Roy, A.G., 2003. Scalings for large turbulent flow structures in gravel-bed rivers. Geophys. Res. Lett. 30, 10.1029/2003GL017553.

Papp, K., 2002. An analysis of volcanic ash plume movement and dispersion within the North Pacific. M.S. Thesis, University of Alaska Fairbanks, 162 p.

Perugini, D., Giampiero, P., 2000. Chaotic dynamics and fractals in magmatic interaction processes: a different approach to the interpretation of mafic microgranular enclaves. Earth Planet. Sci. Lett. 175, 93-103.

Perugini, D., Poli, G., Gatta, G.D., 2002. Analysis and simulation of magma mixing processes in 3D. Lithos 65, 313-330.

Perugini, D., Poli, G., Mazzuoli, R., 2003. Chaotic advection, fractals and diffusion during mixing of magmas: evidence from lava flows. J. Volcanol. Geotherm. Res. 124, 255-279.

Pope, S.B., 2000. Turbulent Flows, Cambridge University Press, 771 p.

Raju, N., Meiburg, E., 1995. The accumulation and dispersion of heavy particles in forced twodimensional mixing layers. Part 2: The effect of gravity. Phys. Fluids 7, 1241-1264. 
Rudman, M., 1992. Two-phase natural convection: implications for crystal-settling in magma chambers. Phys. Earth Planet. Interiors 72, 153-172.

Searcy, C., Dean, K., Stringer, W., 1998. PUFF: A high-resolution volcanic ash tracking model. J. Volcanol. Geotherm. Res. 80, 1-16.

Simakin, A., Schmeling, H., Trubitsyn, V., 1997. Convection in melts due to sedimentary crystal flux from above. Phys. Earth Planet. Interiors 102, 185-200.

Simakin, A., Trubitsyn, V., Schmeling, H., 1994. Structure of the upper boundary layer of a solidifying intrusion with crystal sedimentation. Earth Planet. Sci. Lett. 126, 333-349.

Smith, M.K., 1988. Thermal convection during the directional solidification of a pure liquid with variable viscosity. J. Fluid Mech. 188, 547-570.

Snyder, D., 2000. Thermal effects of the intrusion of basaltic magma into a more silicic magma chamber and implications for eruption triggering. Earth Planet. Sci. Lett. 175, 257-273.

Solomon, T.H., Mezic, I., 2003. Uniform resonant chaotic mixing in fluid flows. Nature 425, 376-380.

Sparks, R.S.J., Barclay, J., Calder, E.S., Herd, R.A., Komorowski, J.C., Luckett, R., Norton, G.E., Ritchie, L.J., Voight, B., Woods, A.W., 2002. Generation of a debris avalanche and violent pyroclastic density current on 26 December (Boxing Day) 1997 at Soufriere Hills volcano, Montserrat. In: Druitt, T.H., Kokelaar, B.P. (Editors), The Eruption of the Soufriere Hills Volcano, Montserrat 1995 to 1999. Geol. Soc. London Mem. 21, 409-434.

Sparks, R.S.J., Bursik, M.I., Carey, S.N., Gilbert, J.S., Glaze, L.S., Sigurdsson, H., Woods, A.W., 1997. Volcanic plumes, John Wiley \& Sons, 574 p.

Sparks, R.S.J, Carey, S.N., Sigurdsson, H., 1991. Sedimentation from gravity currents generated by turbulent plumes, Sedimentology 38, 839-856.

Sparks, R.S.J., Huppert, H.E., Turner, J.S., 1984. The fluid dynamics of evolving magma chambers. Phil. Trans. Royal Soc. London A310, 511-534.

Stix, J., 2001. Flow evolution of experimental gravity currents: Implications for pyroclastic flows at volcanoes, J. Geology 109, 381-398.

Thomas, N., Tait, S., Koyaguchi, T., 1993. Mixing of stratified liquids by the motion of gas bubbles: application to magma mixing. Earth Planet. Sci. Lett. 115, 161-175.

Turner, J.S., Gustafson, L.B., 1981. Fluid motions and compositional gradients produced by crystallization or melting at vertical boundaries, J. Volcanol. Geotherm. Res. 11, 93-125.

Valentine, G., 1987. Stratified flow in pyroclastic surges. Bull. Volcanol. 49, 616-630.

Weinstein, S.A., Yuen, D.A., Olson, P.L., 1988. Evolution of crystal-settling in magma-chamber convection, Earth Planet. Sci. Let. 87, 237-248.

Woods, A.W., Bursik, M.I., Kurbatov, A.V., 1998. The interaction of ash flows with ridges. Bull. Volcanol. 60, 38-51.

Zhang, D.Z., VanderHeyden, W.B., 2002. The effect of mesoscale structures on the macroscopic momentum equations for two-phase flows. Int. J. Multiphase Flow 28, 805-822. 
Table 1. Summary of parameters used to scale experimental works in Figs. 6-8.

\begin{tabular}{|c|c|c|c|c|c|c|c|c|c|}
\hline $\operatorname{Ref}_{a}$ & $\begin{array}{c}d \\
\mu \mathrm{m}\end{array}$ & $\begin{array}{c}\mu \\
\mathrm{Pas}\end{array}$ & $\begin{array}{c}\rho_{f} \\
\mathrm{~kg} / \mathrm{m}^{3}\end{array}$ & $\begin{array}{c}\rho_{p} \\
\mathrm{~kg} / \mathrm{m}^{3}\end{array}$ & $\begin{array}{c}U \\
\mathrm{~m} / \mathrm{s}\end{array}$ & $\underset{\mathrm{m} / \mathrm{s}}{\Delta U \min .}$ & $\begin{array}{l}L \\
\mathrm{~m} \\
\end{array}$ & $\begin{array}{c}\delta \text { min. } \\
\mathrm{m}\end{array}$ & Apparatus \\
\hline \multicolumn{10}{|c|}{ Volcanic plumes } \\
\hline 1. & $38-60$ & $10^{-3}$ & 1000 & 2470 & $0.05-0.1$ & 0.0125 & $0.007-0.25$ & $710^{-4}$ & Water tank \\
\hline 2. & $28-131$ & $10^{-3}$ & $\begin{array}{c}1000- \\
1021\end{array}$ & 3210 & $0.07-0.018$ & 0.007 & $0.09-0.15$ & 0.09 & Water tank \\
\hline 3. & $135-328$ & $10^{-3}$ & 1000 & 3210 & $0.016-0.053$ & 0.0133 & $0.006-1.3$ & 0.006 & Water tank \\
\hline 4. & $23-53$ & $10^{-3}$ & 1000 & 3217 & $0.018-0.029$ & 0.018 & $0.05-0.2$ & 0.05 & Water tank \\
\hline 5. & $4.5-36.5$ & $10^{-3}$ & $\begin{array}{l}1000- \\
1037\end{array}$ & 3217 & $\begin{array}{c}1.3510^{-3}- \\
2.910^{-3}\end{array}$ & $1.3510^{-3}$ & $0.01-0.035$ & 0.01 & Water tank \\
\hline 6. & $9-25$ & $10^{-3}$ & $\begin{array}{l}1000- \\
1030\end{array}$ & 3218 & $0.12-2.4$ & 0.03 & 0.03 & 0.005 & Water tank \\
\hline 7. & $28-131$ & $10^{-3}$ & $\begin{array}{l}1000- \\
1021\end{array}$ & 3210 & $0.007-0.018$ & 0.007 & $0.052-0.08$ & 0.08 & Water tank \\
\hline \multicolumn{10}{|c|}{ Pyroclastic surges } \\
\hline 8. & $23-37$ & $10^{-3}$ & 1000 & 3217 & $\begin{array}{l}0.0036- \\
0.0996\end{array}$ & 0.0249 & $0.01-0.14$ & 0.014 & Water tank \\
\hline 9. & $\begin{array}{l}31- \\
410^{3}\end{array}$ & $10^{-3}$ & 1000 & $\begin{array}{l}1440- \\
3200\end{array}$ & $0.09-0.61$ & 0.0225 & 0.01-0.08 & 0.001 & Water tank \\
\hline 10. & $44-707$ & $10^{-3}$ & 1000 & 2200 & $0.192-1.12$ & 0.048 & $0.15-0.3$ & 0.015 & Water tank \\
\hline 11. & $123-390$ & $10^{-3}$ & 1000 & $\begin{array}{c}2420- \\
2650\end{array}$ & 0.06 & 0.015 & 0.4 & 0.04 & Water tank \\
\hline 12. & $210-297$ & $\begin{array}{l}9.210^{-4}- \\
7.410^{-4}\end{array}$ & $\begin{array}{l}1014- \\
1142\end{array}$ & $\begin{array}{l}1143- \\
1196\end{array}$ & $0.01-0.4$ & 0.1 & $0.06-0.12$ & 0.012 & Water tank \\
\hline 13. & 100 & $10^{-3}$ & 1030 & $\begin{array}{c}2400- \\
2600\end{array}$ & $0.01-0.1$ & 0.01 & $0.05-0.1$ & 0.01 & Water tank \\
\hline \multicolumn{10}{|c|}{ Powder snow avalanches } \\
\hline 14. & $10-100$ & $10^{-5}$ & 1 & $\begin{array}{c}4000- \\
5000\end{array}$ & $0.08-0.3$ & 0.02 & $0.1-0.2$ & 0.01 & Chute flow \\
\hline 14. & $\begin{array}{l}10^{4}- \\
210^{5}\end{array}$ & $10^{-5}$ & 1 & 100 & 6 & 1.5 & $150-300$ & 20 & $\begin{array}{l}\text { Provoked snow } \\
\text { avalanche }\end{array}$ \\
\hline \multicolumn{10}{|c|}{ Volcanic plumes and pyroclastic surges } \\
\hline 15. & $90-500$ & $10^{-5}$ & 1 & 2000 & $10-100$ & 2.5 & 0.1 & 0.01 & $\begin{array}{l}\text { Vertical shock } \\
\text { tube }\end{array}$ \\
\hline \multicolumn{10}{|c|}{ Magmas } \\
\hline 16. & $\begin{array}{l}310^{3}- \\
1.110^{4}\end{array}$ & $\begin{array}{l}6.310^{-4}- \\
2.06\end{array}$ & $\begin{array}{l}1260- \\
1287\end{array}$ & 2109 & $\begin{array}{l}3.7510^{-6}- \\
1.2510^{-4}\end{array}$ & $3.7510^{-6}$ & 0.23 & 0.001 & $\mathrm{KNO}_{3} \operatorname{tank}$ \\
\hline 17. & 16 & $10^{-3}$ & 1000 & 3217 & $10^{-4}-10^{-3}$ & $10^{-4}$ & 0.2 & 0.02 & Water tank \\
\hline 18. & $\begin{array}{l}510^{3}- \\
210^{4}\end{array}$ & $\begin{array}{c}1.2610^{-3}- \\
0.129\end{array}$ & $\begin{array}{l}1260- \\
1287\end{array}$ & 2109 & $0.05-0.1$ & $10^{-3}$ & 0.2 & 0.01 & $\mathrm{KNO}_{3} \operatorname{tank}$ \\
\hline 19. & $210-500$ & $10^{-3}$ & 1000 & 1033 & $\begin{array}{c}8.1310^{-3}- \\
R e^{\mathrm{b}}\end{array}$ & $810^{-5}$ & $0.1-0.2$ & 0.05 & Water tank \\
\hline 20. & $\begin{array}{l}10^{3}- \\
510^{3}\end{array}$ & $\begin{array}{c}6.310^{-4}- \\
0.001\end{array}$ & $\begin{array}{l}1160- \\
1358\end{array}$ & $\begin{array}{l}1140- \\
2284\end{array}$ & $10^{-7}-10^{-4}$ & $10^{-7}$ & 0.15 & 0.001 & $\mathrm{NaCO}_{3}$ tank \\
\hline 21. & $10^{3}$ & 160 & 1477 & 2600 & $2.7810^{-6}$ & $2.7810^{-6}$ & 0.2 & 0.1 & Sucrose tank \\
\hline \multicolumn{10}{|c|}{ Magmas and pyroclastic surges } \\
\hline 22. & 1320 & $10^{-3}$ & 1000 & 1000 & $0.162-5.576$ & 0.162 & 0.0108 & $1.0810^{-}$ & Couette flow \\
\hline 22. & 35 & $10^{-5}$ & 1 & 2200 & $1.72-3.9$ & 0.975 & 0.09 & 0.009 & Chute flow \\
\hline
\end{tabular}

${ }^{a}$ References are: 1. Cardoso and Zarrebini (2000); 2. Carey et al. (1988); 3. Ernst et al. (1996); 4. Hogg and Huppert (2001); 5. Hoyal et al. (1999); 6. Huppert et al. (1991); 7. Sparks et al. (1991); 8. Bonnecaze et al. (1995); 9. Choux and Druitt (2002); 10. Ghosh et al. (1986); 11. Jobson and Sayre (1970); 12. Stix (2001); 13. Woods et al. (1998); 14. Bozhinskiy and Sukhanov (1998); 15. Anilkumar et al. (1993); 16. Huppert et al. (1983); 17. Koyaguchi et al. (1990); 18. Martin (1990); 19. Martin and Nokes (1989); 20. Turner and Gustafson (1981); 21. Weinstein et al. (1988); 22. Bagnold (1954).

${ }^{b}$ The upper bound of Reynolds number was calculated from Rayleigh and Prantl numbers. 
Table 2: Common ranges of the dynamic variables of three magmatic systems.

\begin{tabular}{|c|c|c|c|c|c|}
\hline variable & unit & range & $\begin{array}{l}\text { volcanic } \\
\text { plumes }\end{array}$ & $\begin{array}{l}\text { pyroclastic } \\
\text { surges }\end{array}$ & $\begin{array}{c}\text { magmatic } \\
\text { liquids }\end{array}$ \\
\hline \multirow[t]{2}{*}{$\delta$} & $\mathrm{mm}$ & $\min$ & 0.015 & 0.015 & 0.015 \\
\hline & & $\max$ & 32 & 1024 & 1 \\
\hline \multirow[t]{2}{*}{$\mu$} & $\mathrm{Pa} \mathrm{s}$ & $\min$ & $310^{-5}$ & $310^{-5}$ & $10^{3}$ \\
\hline & & $\max$ & $310^{-5}$ & $310^{-5}$ & $10^{8}$ \\
\hline \multirow[t]{2}{*}{$\rho_{f}$} & $\mathrm{~kg} \mathrm{~m}^{-3}$ & $\min$ & 0.1 & 1 & 2200 \\
\hline & & $\max$ & 1 & 1 & 2800 \\
\hline \multirow[t]{2}{*}{$\rho_{p}$} & $\mathrm{~kg} \mathrm{~m}^{-3}$ & $\min$ & 1000 & 1000 & 2200 \\
\hline & & $\max$ & 2500 & 2500 & 2400 \\
\hline \multirow[t]{2}{*}{$\rho_{p} / \rho_{f}$} & & $\min$ & 25000 & 2500 & 1.09 \\
\hline & & $\max$ & 1000 & 1000 & 0.79 \\
\hline \multirow[t]{2}{*}{$U$} & $\mathrm{~m} \mathrm{~s}^{-1}$ & $\min$ & 10 & 10 & 0 \\
\hline & & $\max$ & 50 & 200 & 1 \\
\hline$\Delta U^{\mathrm{a}}$ & $\mathrm{m} \mathrm{s}^{-1}$ & $\min$ & 2.5 & 2.5 & 0 \\
\hline \multirow[t]{2}{*}{$L$} & $\mathrm{~m}$ & $\min$ & 1200 & 10 & 10 \\
\hline & & $\max$ & 3900 & 1000 & 1000 \\
\hline$\delta^{\mathrm{b}}$ & $\mathrm{m}$ & $\min$ & 120 & 1 & 10 \\
\hline \multirow[t]{2}{*}{$R e$} & & $\min$ & $4.010^{7}$ & $3.310^{6}$ & 0 \\
\hline & & $\max$ & $6.510^{9}$ & $6.710^{9}$ & $2.810^{3}$ \\
\hline \multirow[t]{2}{*}{$S_{T}$} & & $\min$ & $9.410^{-6}$ & $1.110^{-3}$ & 0 \\
\hline & & $\max$ & $2.010^{2}$ & $9.710^{7}$ & $1.110^{-9}$ \\
\hline \multirow[t]{2}{*}{$\Sigma_{T}$} & & $\min$ & $4.510^{-5}$ & $2.810^{-6}$ & 0 \\
\hline & & $\max$ & $7.710^{4}$ & $9.710^{9}$ & $1.110^{5}$ \\
\hline
\end{tabular}

${ }^{a}$ Minimum speed of unsteadiness $\Delta U$ equals $U_{\min }$ if $\operatorname{Re}<10^{4}$ and $U_{\min } / 4$ if $\operatorname{Re}>10^{4}$.

${ }^{\mathrm{b}}$ Minimum size of unsteadiness $\delta$ equals $L_{\min }$ if $\operatorname{Re}<10^{4}$ and $L_{\min } / 10$ if $R e>10^{4}$. 
Table 3: Estimates of the dynamic variable of two magmatic mixtures.

\begin{tabular}{|c|c|c|c|}
\hline variable & unit & $\begin{array}{l}\text { Olivine in } \\
\text { basalt }\end{array}$ & $\begin{array}{l}\text { Orthopyroxene } \\
\text { in andesite }\end{array}$ \\
\hline$\rho_{p}$ & $\mathrm{~kg} \mathrm{~m}^{-3}$ & 3220 & 3171 \\
\hline$d$ & $\mathrm{~mm}$ & $2-4$ & $1-2$ \\
\hline$\mu_{f}$ & Pa s & $50-200$ & $1.210^{6}$ \\
\hline$\mu_{m}$ & $\mathrm{~Pa} \mathrm{~s}$ & $85-2200$ & $2.610^{5}$ \\
\hline$\rho_{f}$ & $\mathrm{~kg} \mathrm{~m}^{-3}$ & 2700 & 2237 \\
\hline$\rho_{m}$ & $\mathrm{~kg} \mathrm{~m}^{-3}$ & 2400 & 2212 \\
\hline$L$ & $\mathrm{~m}$ & 100 & 1000 \\
\hline$B$ & $\mathrm{~m}^{2} \mathrm{~s}^{-3}$ & $4.110^{-8}$ & $6.510^{-10}$ \\
\hline \multirow[t]{2}{*}{$R e$} & $\min$. & 23 & 0.13 \\
\hline & $\max$ & 9 & 0.11 \\
\hline \multirow[t]{2}{*}{$S_{T}$} & $\min$. & $3.410^{-7}$ & $3.310^{-11}$ \\
\hline & $\max$. & $1.810^{-4}$ & $1.310^{-10}$ \\
\hline \multirow[t]{2}{*}{$\Sigma_{T}$} & $\min$. & $4.710^{-3}$ & $9.210^{-7}$ \\
\hline & $\max$ & $1.910^{-2}$ & $3.710^{-6}$ \\
\hline
\end{tabular}




\section{Figure Captions}

Figure 1. Overview of the interactions occurring in volcanic mixtures of particles and a continuous phase (i.e. liquid or gas). The Stokes number $\left(S_{T}\right)$ and the stability number $\left(\Sigma_{T}\right)$ are Lagrangian (instantaneous) scalings that assess whether the fluid transfers momentum to particles, and the Reynolds number $(R e)$ is the Eulerian (average) scaling of the fluid dynamical regime. These three scalings characterize the way particles are transported within the mixture. In the turbulent regime, coupled particles are well mixed, feedback between fluid and particles segregates partly-decoupled particles in mesoscale structures, and fully-decoupled particles have independent trajectories. In the laminar regime, coupled particles are passive tracers, feedback between fluid and particles causes partlydecoupled particles to drift from the fluid streamlines, and fully decoupled particles have independent trajectories. Sedimentation processes differ for each multiphase behavior: Stokes settling refers to the linear sedimentation law in a still fluid, Hazen settling refers to an exponential sedimentation law in a well-mixed fluid, and unsteady settling refers to some intermediate case.

Figure 2. Scales of motion from laminar to turbulent conditions as a function of the Reynolds number (Dimotakis and Catrakis, 1999). $L$ is the outer-scale, $\lambda_{S_{T}}$ and $\lambda_{\Sigma_{T}}$ are the particle length scales, and $\lambda_{0}$ is the Kolmogorov scale.

Figure 3. Possible scales of the continuous phase motions: $U, L, \Delta U$, and $\delta$, encountered in magmatic mixtures, the evaluation of which is necessary to calculate $S_{T}, \Sigma_{T}$, and $R e$. Outerscales $(U$ and $L)$ are tied to macroscopic characteristics of the system, whether volcanic plume, pyroclastic surge, or magmatic chamber. In turbulent, post-conduit volcanic systems, unsteady scales ( $\Delta U$ and $\delta$ ) range from the outer-scale down to the Kolmorogov 
scale. In mostly laminar systems such as convecting magmas, $\Delta U$ and $\delta$ are constrained by viscous plumes. Note that dense systems such as pyroclastic flows cannot be scaled with the framework presented herein.

Figure 4. Schematic view of the emergence of mesoscale structures in turbulent dilute mixtures. Eddies whose forces balance particle drag and inertia are of characteristic sizes $\lambda_{S_{T}}$ and $\lambda_{\Sigma_{T}}$. The strong feedback between fluid and particles leads to transient segregations of particles, which tend to gather in zones of least velocity gradient. Particle gathering causes higher particle concentrations that organize in patterns of sizes between particle size and the outer-scale called mesoscale structures. Note these structures may affect flow dynamics and thus have a major effect on processes like particle aggregation and coalescence.

Figure 5. Example of the variations of length scales $\lambda_{S_{T}}$ and $\lambda_{\Sigma_{T}}$ with particle size one may expect in a pyroclastic surge. Horizontal turbulent air stream $20-\mathrm{m}$ thick at $15 \mathrm{~m} \mathrm{~s}^{-1}$ loaded with $1000 \mathrm{~kg} \mathrm{~m}^{-3}$ particles. Regimes of multiphase particle transport refer to Fig. 1.

Figure 6. Estimates of $R e, S_{T}$, and $\Sigma_{T}$ for experimental work published in relation with volcanic plumes. Fields of multiphase behavior are indicated (see also Fig. 1). Particles in mesoscale structures are subjected to transient transport and sedimentation. Particles with motions independent from the fluid settle out of the flow. Mixture theory applies to wellmixed particles, the behavior of which can be described with the Rouse number. Note that since axes are in logarithmic units, minus infinity represents a zero-value. Parameters and references of experimental studies are in Table 1.

Figure 7. Estimates of $R e, S_{T}$, and $\Sigma_{T}$ for experimental work published in relation with pyroclastic surges. Fields of multiphase behavior are indicated (see also Fig. 1). Particles 
in mesoscale structures are subjected to transient transport and sedimentation. Particles with motions independent from the fluid settle out of the flow. Mixture theory applies to well-mixed particles, the behavior of which can be described with the Rouse number. Note that since axes are in logarithmic units, minus infinity represents a zero-value. Scaling ranges of the December 26, 1997 Montserrat surge (Sparks et al., 2002) and a powdersnow avalanche (Bozhinskiy and Sukhanov, 1998) are also shown within the natural surge field. Parameters and references of experimental studies are in Table 1.Figure 8. Estimates of $R e, S_{T}$, and $\Sigma_{T}$ for experimental work published in relation with magmatic systems. Fields of multiphase behavior are indicated (see also Fig. 1). Particles with motions independent from the fluid settle out of the flow as if it were still. In laminar regime, particles acting as passive tracer follow the chaotic advection of the fluid. Basset and virtual mass forces may be important when $R e$ is transitional, and $\Sigma_{T}$ indicates how buoyant particles are. Note that since axes are in logarithmic units, minus infinity represents a zero-value. Scaling ranges of the Montserrat magmatic system (Couch et al., 2001) are also shown within the natural magmatic field. Parameters and references of experimental studies are in Table 1. 


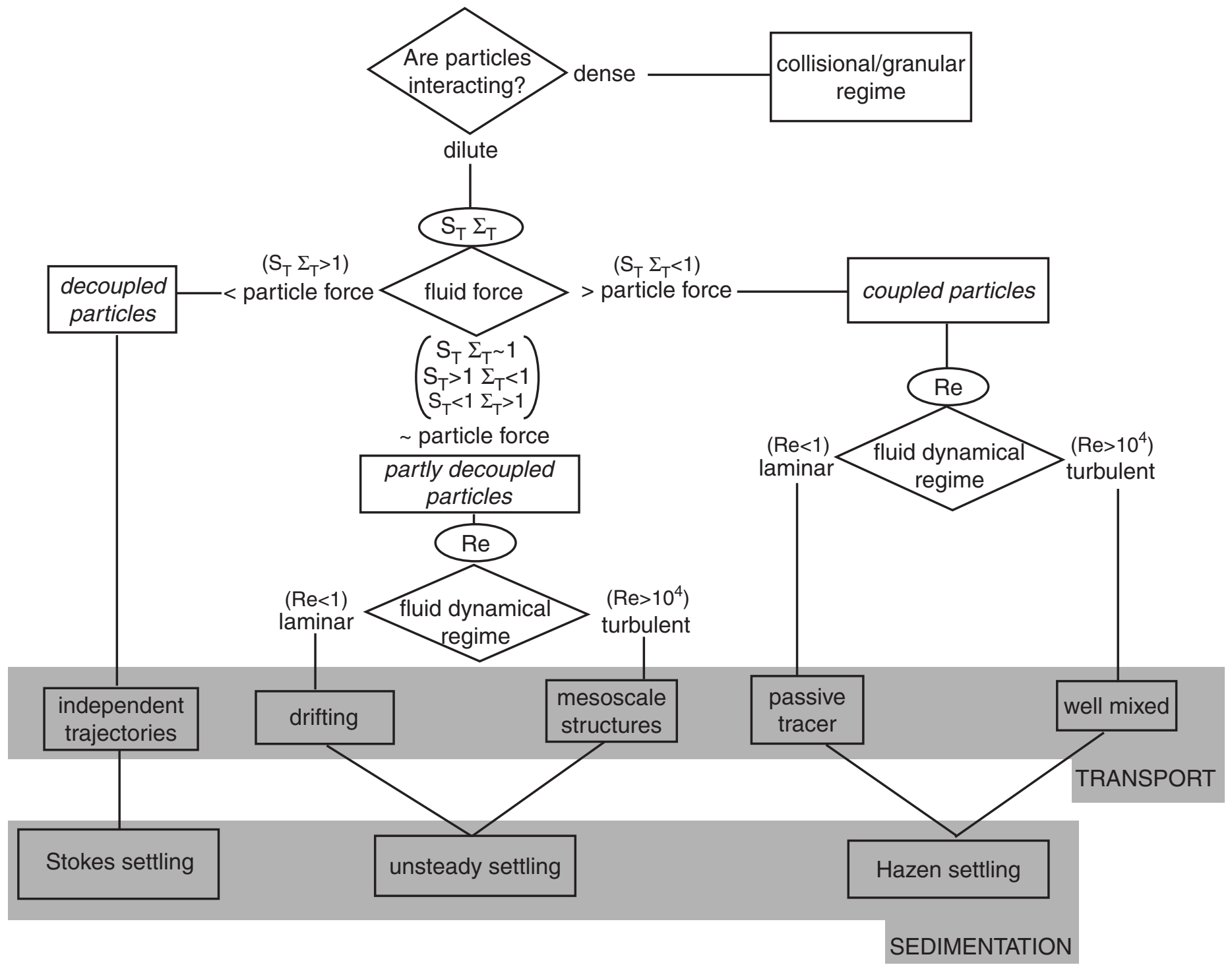

Figure 1 


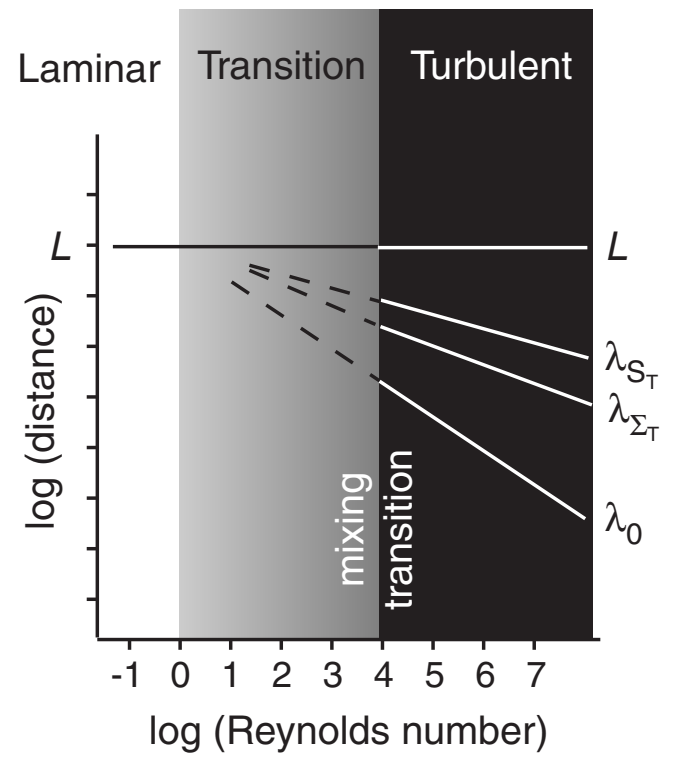

Figure 2 


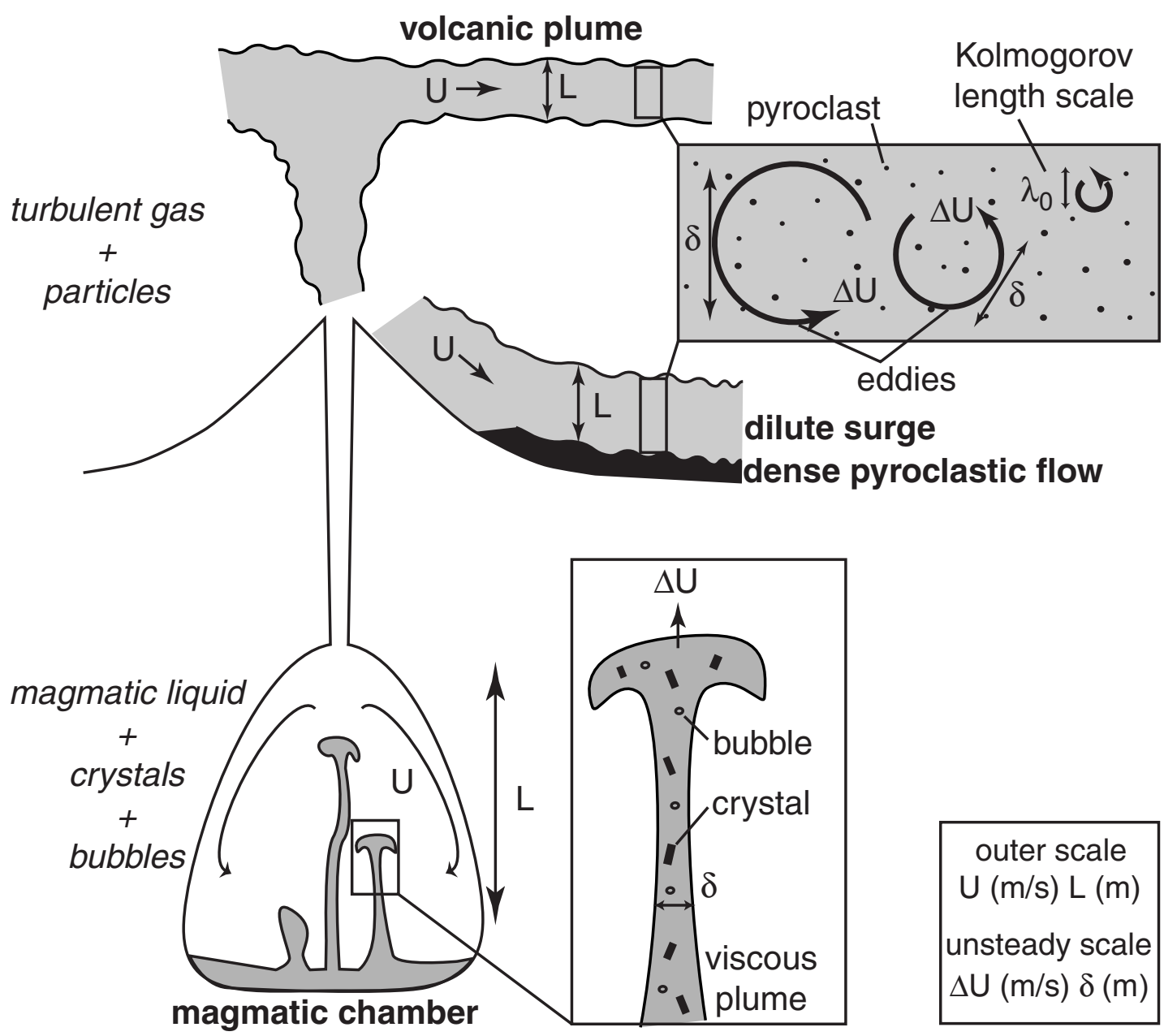

Figure 3 


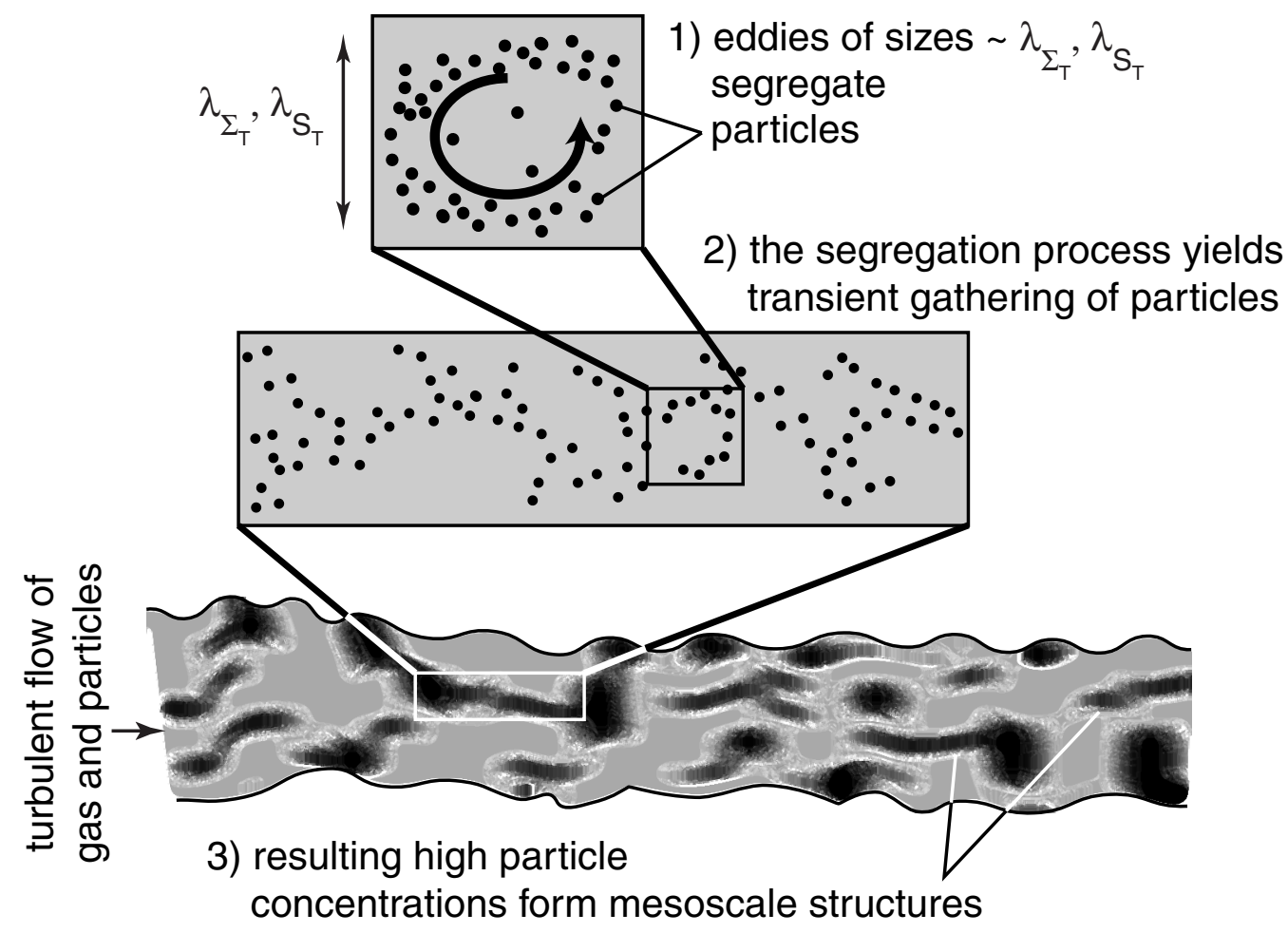

Figure 4 


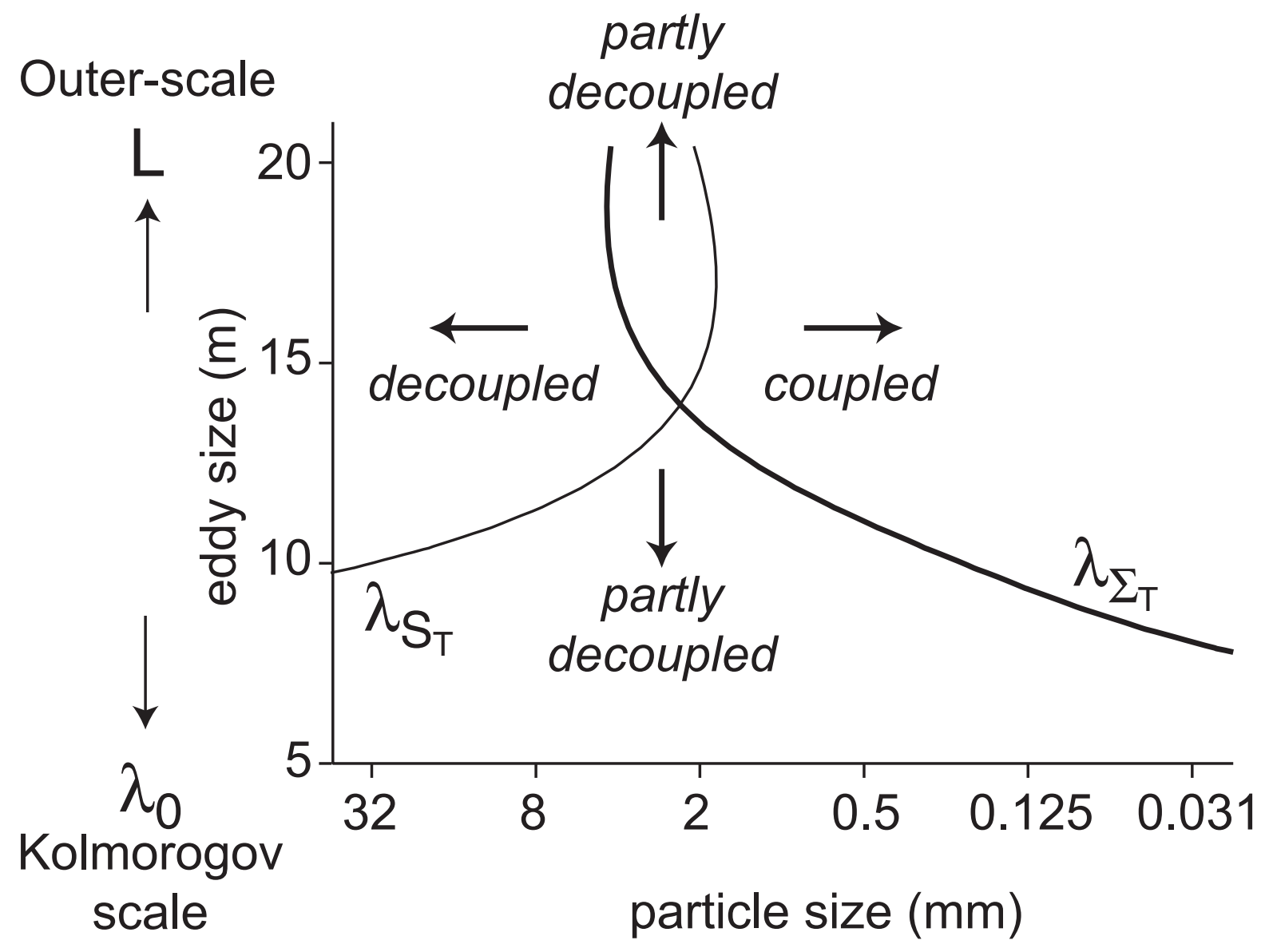

Figure 5 
A.

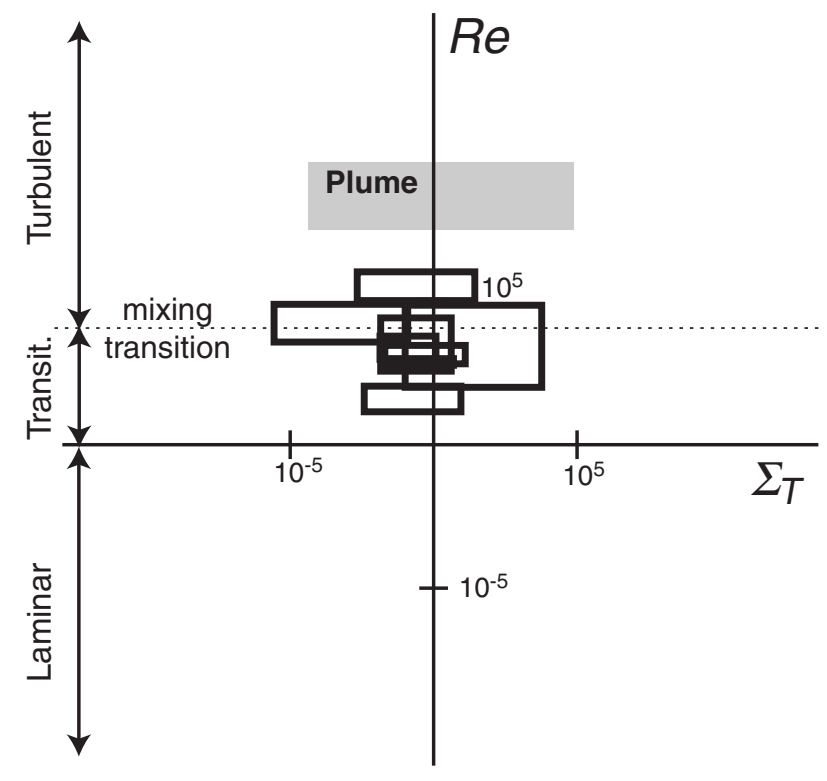

$\square$ Laboratory experiments Natural volcanic plumes
B.

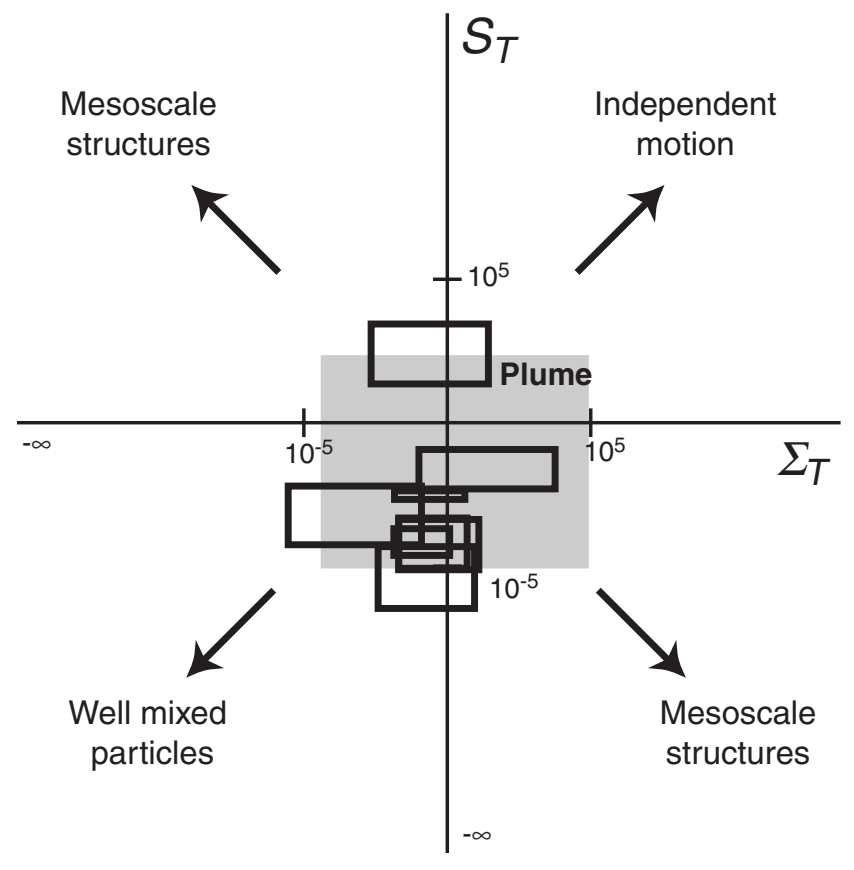

C.

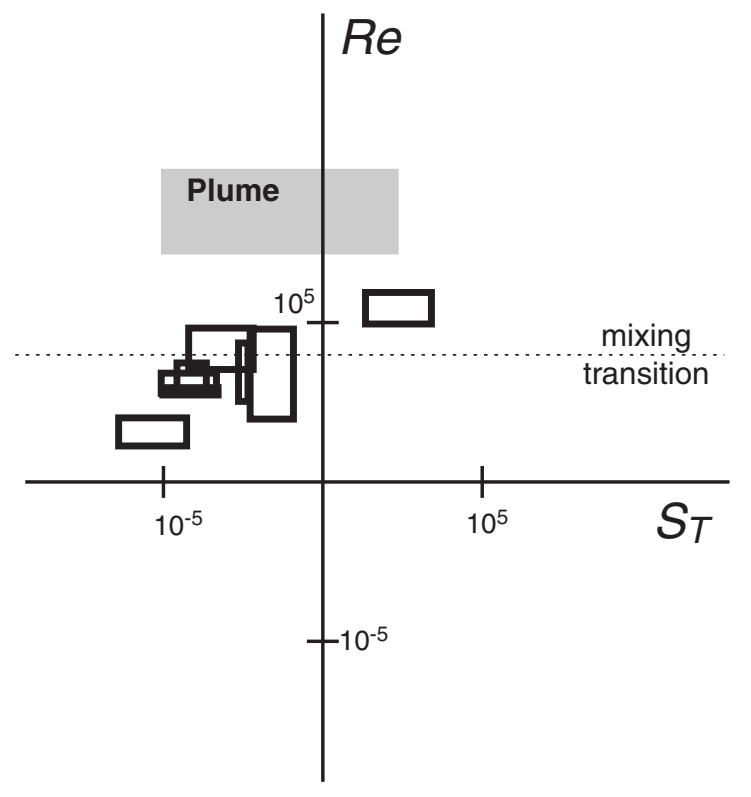

Figure 6 
A.

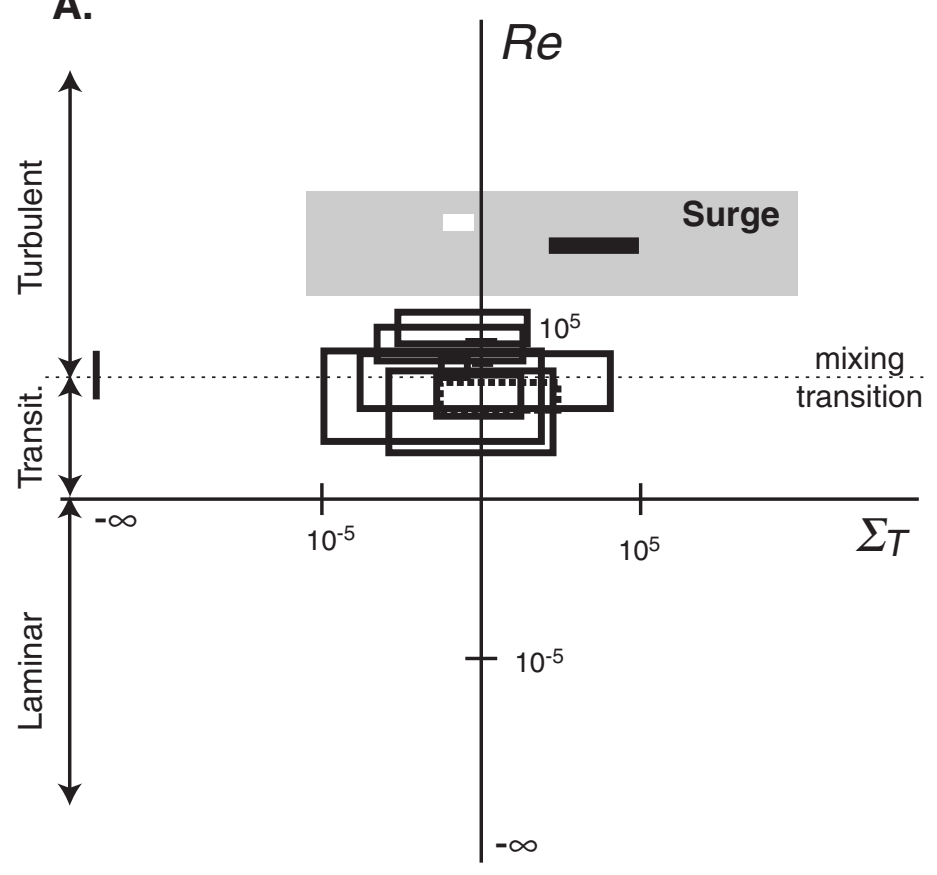

B.

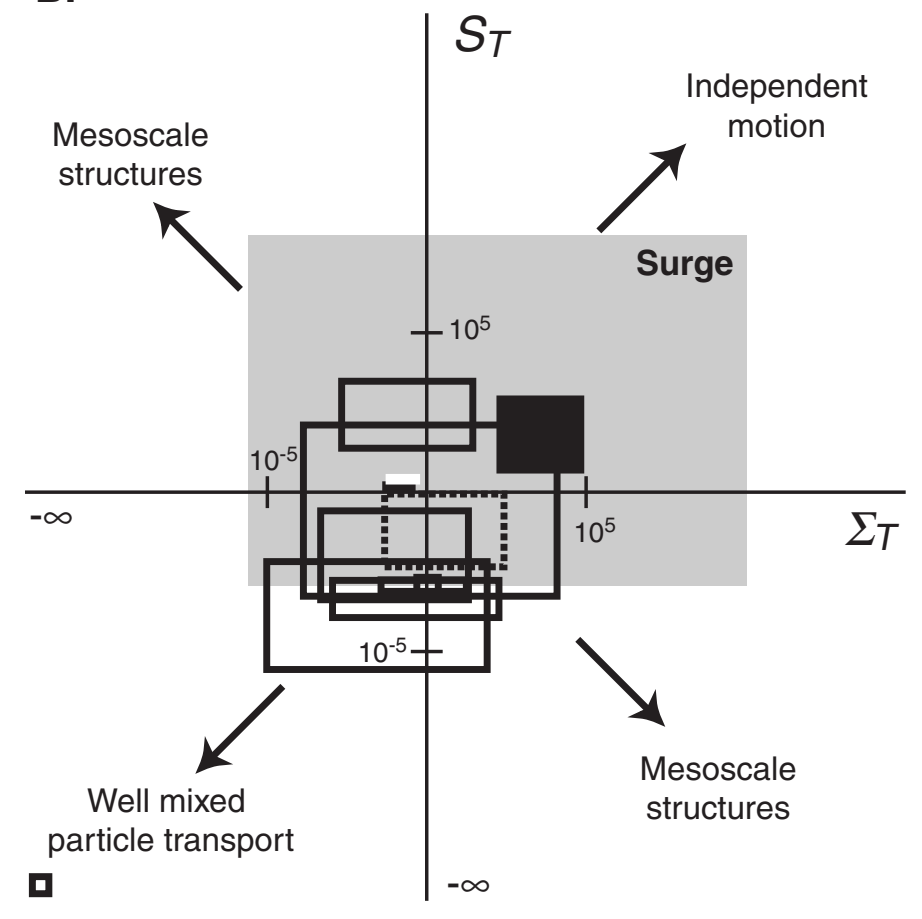

c.

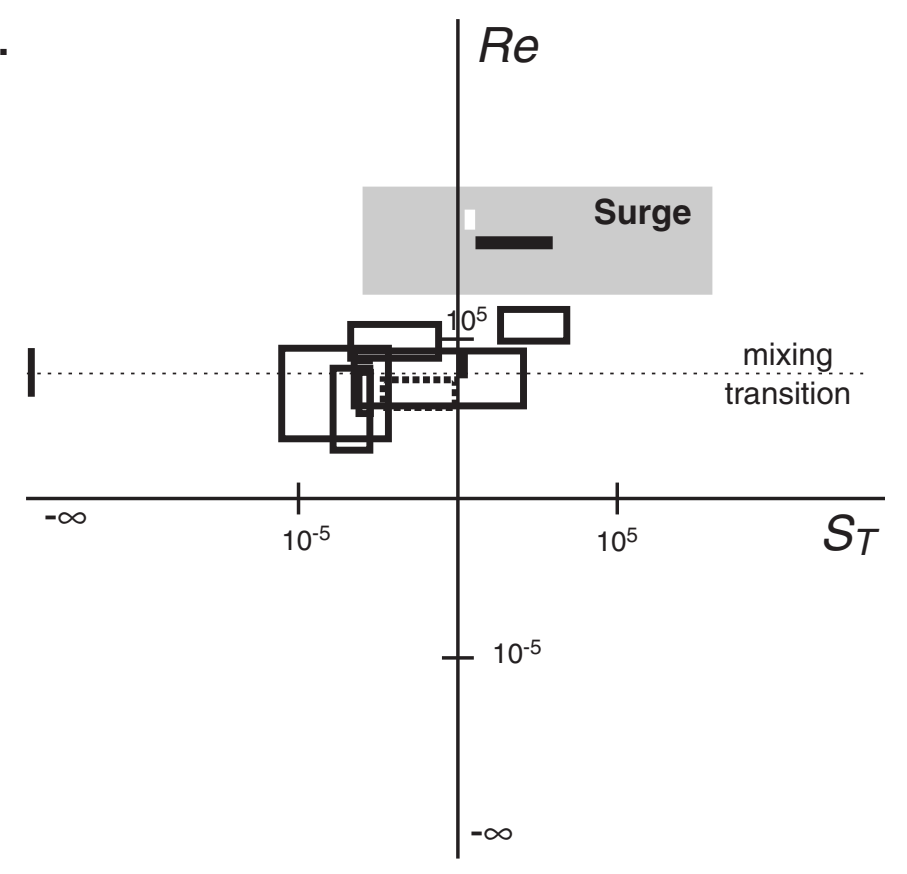

Figure 7 
A.

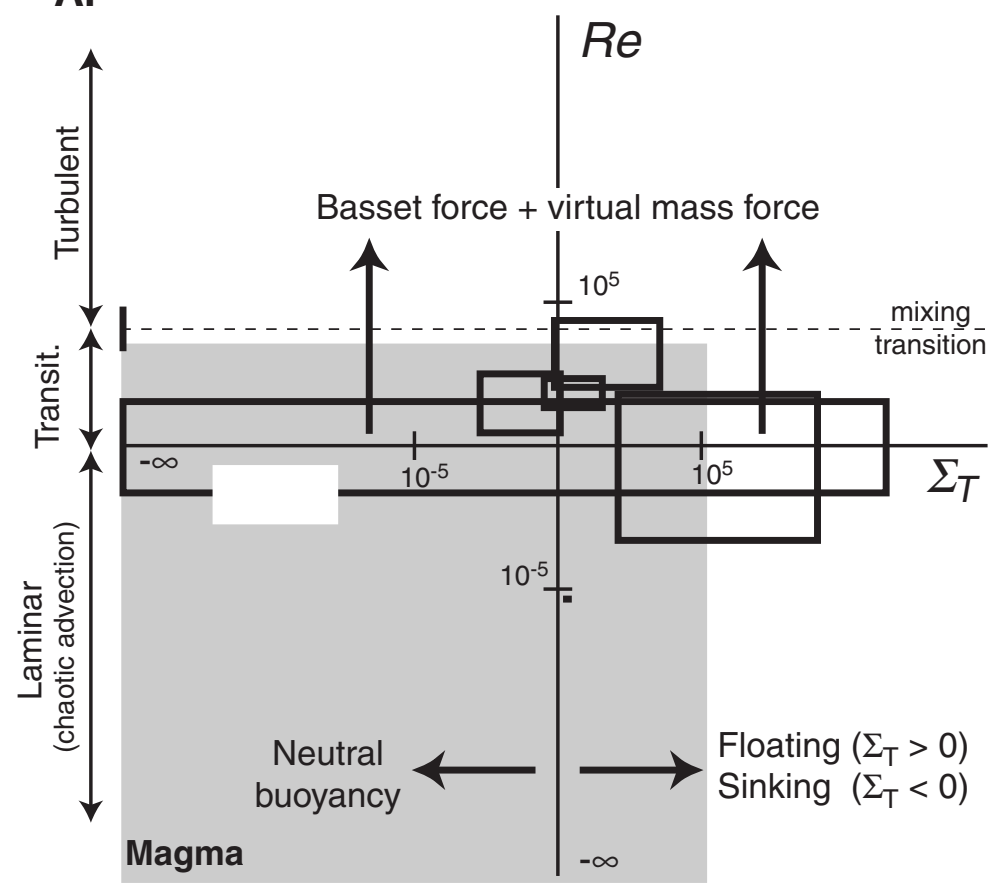

B.

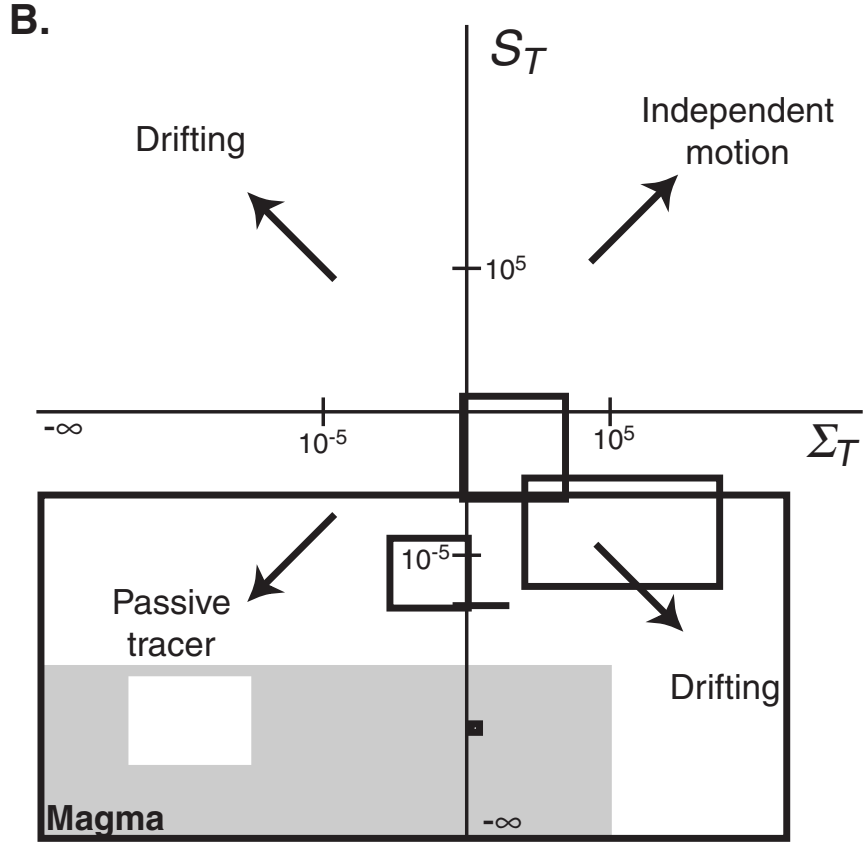

c.

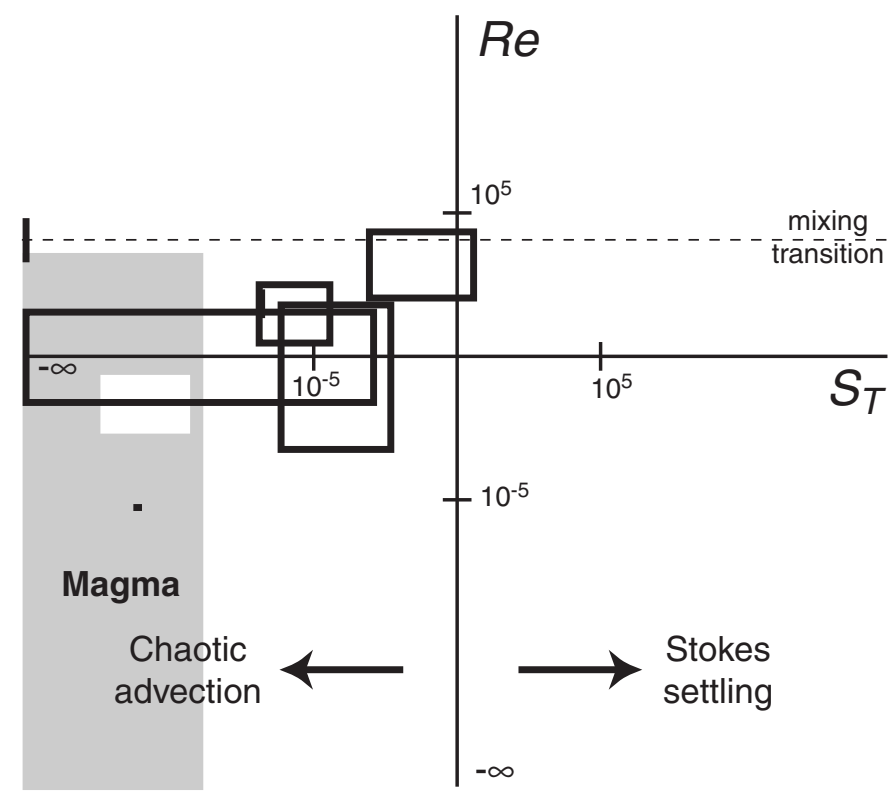

Figure 8 